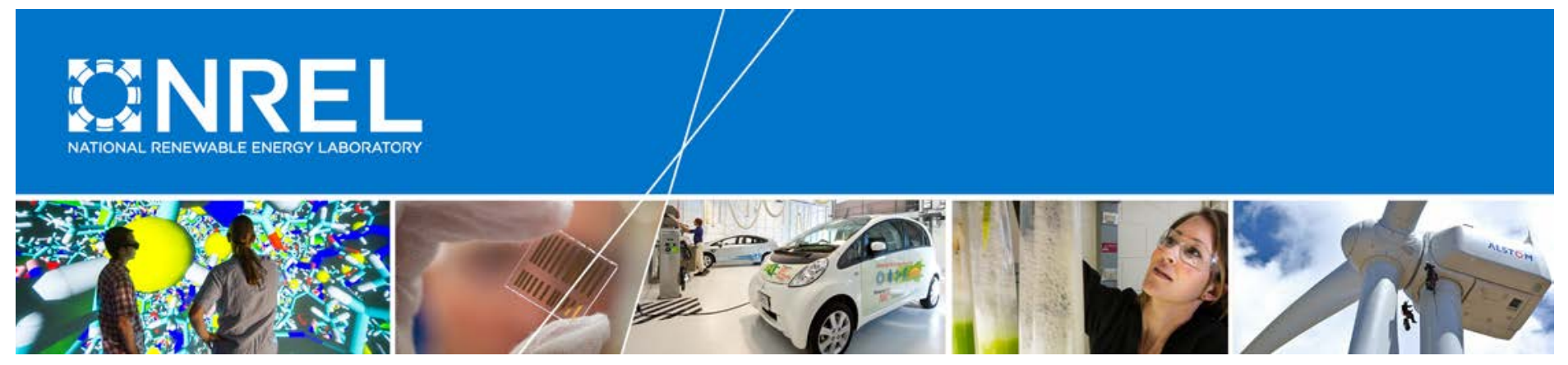

\title{
Remote Sensing of Complex Flows by Doppler Wind Lidar: Issues and Preliminary Recommendations
}

Lead Author: Andrew Clifton National Renewable Energy Laboratory

NREL is a national laboratory of the U.S. Department of Energy Office of Energy Efficiency \& Renewable Energy Operated by the Alliance for Sustainable Energy, LLC

This report is available at no cost from the National Renewable Energy Laboratory (NREL) at www.nrel.gov/publications.

Technical Report

NREL/TP-5000-64634

December 2015 


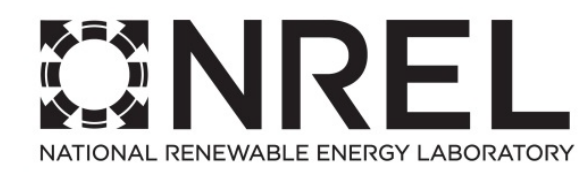

\section{Remote Sensing of Complex Flows by Doppler Wind Lidar: Issues and Preliminary Recommendations}

Lead Author:

Andrew Clifton, National Renewable Energy

Laboratory

Contributing Authors:

Matthieu Boquet, Leosphere

Edward Burin Des Roziers and Annette Westerhellweg, UL International Gmbh - DEWI

Martin Hofsäß, Stuttgart Wind Energy

Tobias Klaas, Fraunhofer Institute for Wind Energy and Energy System Technology

Klaus Vogstad, Meventus

Peter Clive, Sgurr Energy

Mike Harris and Scott Wylie ZephIR Limited

Evan Osler, Renewable NRG Systems

Bob Banta and Aditya Choukulkar, National Oceanic and Atmospheric Administration

Julie Lundquist and Matthew Aitken, University of Colorado Boulder

Prepared under Task No. WE15.3G30

NREL is a national laboratory of the U.S. Department of Energy Office of Energy Efficiency \& Renewable Energy Operated by the Alliance for Sustainable Energy, LLC

This report is available at no cost from the National Renewable Energy Laboratory (NREL) at www.nrel.gov/publications.

Technical Report

NREL/TP-5000-64634

December 2015

Contract No. DE-AC36-08GO28308
National Renewable Energy Laboratory 15013 Denver West Parkway Golden, CO 80401

303-275-3000 • www.nrel.gov 


\section{NOTICE}

This report was prepared as an account of work sponsored by an agency of the United States government. Neither the United States government nor any agency thereof, nor any of their employees, makes any warranty, express or implied, or assumes any legal liability or responsibility for the accuracy, completeness, or usefulness of any information, apparatus, product, or process disclosed, or represents that its use would not infringe privately owned rights. Reference herein to any specific commercial product, process, or service by trade name, trademark, manufacturer, or otherwise does not necessarily constitute or imply its endorsement, recommendation, or favoring by the United States government or any agency thereof. The views and opinions of authors expressed herein do not necessarily state or reflect those of the United States government or any agency thereof.

This report is available at no cost from the National Renewable Energy Laboratory (NREL) at www.nrel.gov/publications.

Available electronically at SciTech Connect http:/www.osti.gov/scitech

Available for a processing fee to U.S. Department of Energy and its contractors, in paper, from:

U.S. Department of Energy

Office of Scientific and Technical Information

P.O. Box 62

Oak Ridge, TN 37831-0062

OSTI http://www.osti.gov

Phone: 865.576.8401

Fax: 865.576.5728

Email: reports@osti.gov

Available for sale to the public, in paper, from:

U.S. Department of Commerce

National Technical Information Service

5301 Shawnee Road

Alexandria, VA 22312

NTIS http://www.ntis.gov

Phone: 800.553 .6847 or 703.605 .6000

Fax: 703.605.6900

Email: orders@ntis.gov 


\section{Preface}

Participants in the International Energy Agency (IEA) Wind Task 32, Wind Lidar Systems for Wind Energy Deployment (Task 32), prepared this report.

A goal of Task 32 was to create (or support the creation of) recommended practices for the use of lidar for various applications. These applications include, but are not limited to, resource assessment, turbine control and operation, and floating lidar use.

In the area of wind resource assessment, Task 32 supported the review and improvement of recommended practice number 15 from the IEA's Expert Group Study on Recommended Practices (shortened to RP15; Clifton et al. [2013]). Work on RP15 was greatly helped by summaries of the state of the art in sodar measurements (Moore 2011) and lidar measurements (Jaynes and Courtney 2011). RP15 is limited to the use of remote sensing in simple flow conditions.

A work package was formed in 2012 to start developing recommended practices for using lidar in complex flow because wind resource assessment and other lidar measurements also take place in complex flow conditions. The first activity of that group was to develop a summary of the state of the art in using Doppler wind lidar in complex flow. This report is that summary, which will enable the future development of recommended practices.

Comments on this report should be sent to Andrew Clifton at the U.S. Department of Energy's National Renewable Energy Laboratory (andrew.clifton@,nrel.gov). 


\section{Acknowledgments}

This work was supported by the U.S. Department of Energy under Contract No. DE-AC3608GO28308 with the National Renewable Energy Laboratory. Funding for the work was provided by the DOE Office of Energy Efficiency and Renewable Energy, Wind and Water Power Technologies Office.

This document benefited from contributions from IEA Task 32 participants in many different countries:

- Matthieu Boquet, Leosphere, Orsay, France

- Martin Hofsäß, Stuttgart Wind Energy, Stuttgart, Germany

- Edward Burin Des Roziers and Annette Westerhellweg, UL International Gmbh - DEWI, Wilhelmshaven, Germany

- Tobias Klaas, Fraunhofer Institute for Wind Energy and Energy System Technology (IWES), Kassel, Germany

- Klaus Vogstad, Meventus, Kristiansand, Norway

- Peter Clive, Sgurr Energy, Glasgow, UK

- Mike Harris and Scott Wylie, ZephIR Limited, Ledbury, UK

- Evan Osler, Renewable NRG Systems, Hinesburg, Vermont, USA

- Bob Banta and Aditya Choukulkar, National Oceanic and Atmospheric Administration, Boulder, Colorado, USA

- Julie Lundquist and Matthew Aitken, University of Colorado - Boulder, Boulder, Colorado, USA 


\section{List of Abbreviations}

$\circ$

CFD

DBS

IEA

IEC

met

RHI

RP

VAD degree

computational fluid dynamics

Doppler beam swinging

International Energy Agency

International Electrotechnical Commission

meteorological

range-height indicator

recommended practice

velocity azimuth display 


\section{Executive Summary}

Remote sensing of winds using lidar has become popular and useful in the wind energy industry. Extensive experience has been gained in using lidar for applications including land-based and offshore resource assessment, plant operations, and turbine control.

This report was prepared by members of Task 32. It describes the state of the art in the use of Doppler wind lidar for the assessment of wind conditions in complex flows for wind energy applications. The report will be used as input for future recommended practices on this topic.

The state of the art is explained using data needs, situations, and methods that combine to create specific use cases for lidar in complex flows. Each use case should be validated individually, and any bias and uncertainty relative to traditional point measurements should be explainable by a physics-based model. This approach will allow use cases to be applied at new sites with validated bias and uncertainty estimates that are based on previous experience.

The use cases described in this report are the most common at the time of writing and do not represent an exhaustive or complete list. This list can be extended in future by the definition of further use cases. The use cases covered in this report are as follows:

- Conical scanning lidar (with a fixed elevation angle)

- Flow reconstruction from conical scans in homogenous flows

- Flow modeling to convert wind lidar measurements to point values

- Flow reconstruction from conical scans without assuming homogeneous flow

$\circ$ Vertical beam use to reduce uncertainty in the vertical component

- Use of a smaller lidar sampling volume to reduce differences compared to cups

- Use of a short met mast to scale lidar measurements.

- Scanning lidar (with azimuth and elevation angle degrees of freedom)

- Use of conical sector or slice scans to qualitatively identify flow features

- Flow reconstruction from conical sector or slice scans in complex flows

- Scanning lidar use for quantitative analysis of wakes

- Multiple lidar use to measure wind vectors.

This report presents several preliminary recommendations for using lidar in complex flow:

- Define complex flow based on terrain or meteorological conditions.

- Select an appropriate measurement method for the use case.

- Validate each individual use case.

- Follow IEA Wind RP15 validation methods for simple flow conditions. 


\section{Table of Contents}

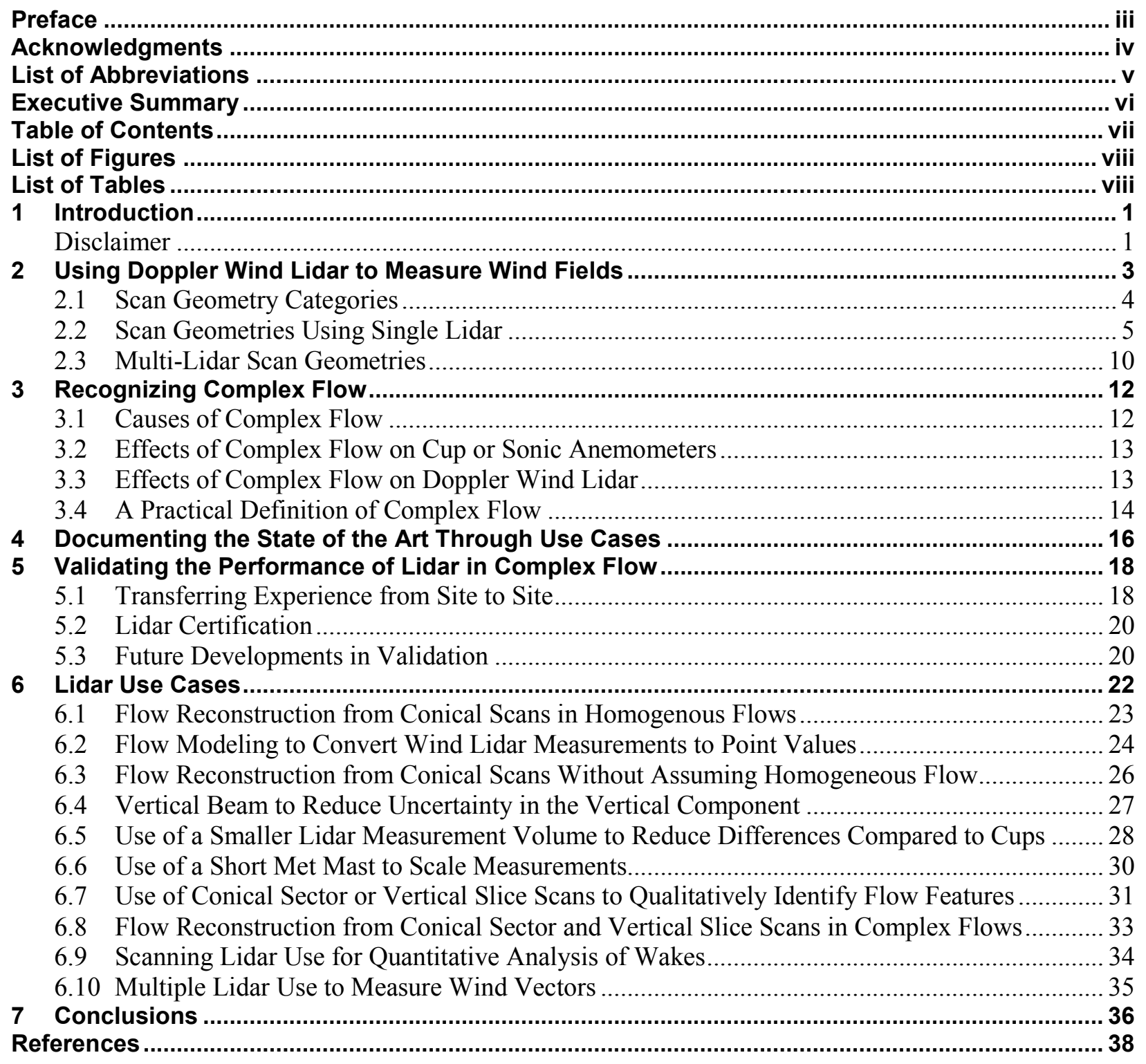




\section{List of Figures}

Figure 1. Schematic representation of a Doppler wind lidar system

Figure 2. Illustration of the relationship between the wind vector and the radial velocity observed by a lidar

Figure 3. Different categories of wind lidar and associated scan geometries ......................................... 5

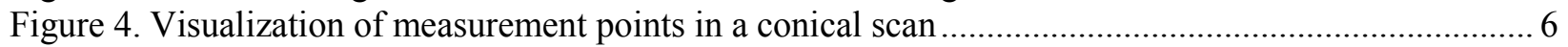

Figure 5. Visualization of measurement points in a DBS scan ........................................................... 7

Figure 6. Visualization of measurement points in a conical sector scan .............................................. 7

Figure 7. Visualization of measurement points in a vertical slice ....................................................... 8

Figure 8. Visualization of measurement points in a compound conical scan .......................................... 9

Figure 9. Visualization of measurement points in a stacked conical sector scan..................................... 10

Figure 10. Indicators of complex flow that may be important for comparisons of lidar and point measurements

Figure 11. How the data requirements, the conditions, and methods relate to each other and combine to define a specific lidar use case

Figure 12. An illustration of the effect of terrain on the flow in the volume observed by a profiling Doppler wind lidar, versus the flow observed by a point measurement on a tower. ............. 25

Figure 13. Use of a vertical beam to constrain the results of flow reconstruction from a conical scan...... 27

Figure 14. Reducing the cone angle to reduce the volume of a conical scan.........................................2 29

Figure 15. Using a low-elevation conical sector scan to detect and quantify a wind turbine wake............ 32

\section{List of Tables}

Table 1. Flow Reconstruction from Conical Scans in Homogenous Flows............................................. 23

Table 2. Flow Modeling to Convert Wind Lidar Measurements to Point Values ..................................... 24

Table 3. Flow Reconstruction from Conical Scans Without Assuming Homogeneous Flow ..................... 26

Table 4. Vertical Beam Use to Reduce Uncertainty in the Vertical Component ..................................... 27

Table 5. Use of a Smaller Lidar Sampling Volume to Reduce Differences Compared to Cups ................ 28

Table 6. Use of a Met Tower to Scale Lidar Measurements.................................................................... 30

Table 7. Using Conical Sectors or Vertical Slices to Qualitatively Identify Flows.................................. 31

Table 8. Flow Reconstruction from Conical Sector Scans and Vertical Slices in Complex Flows............ 33

Table 9. Scanning Lidar Use for Quantitative Analysis of Wakes ......................................................... 34

Table 10. Multiple Lidar Use to Measure Wind Vectors ........................................................................... 35 


\section{Introduction}

Recent years have seen a rapid growth in the use of remote sensing, in particular lidar, to collect wind data for wind energy applications. As a response to this growth and to foster international sharing of experience, the International Energy Agency (IEA) set up Wind Task 32, Wind Lidar Systems for Wind Energy Deployment (Task 32). This task is designed to explore the use of lidar for various wind energy applications, including, but not limited to: calibration; resource and site assessment on land and offshore; and turbine monitoring, control, and operation. Task 32 has the ultimate goal of developing recommended practices to help in the adoption of lidar by the wind energy industry. Recommended practices are typically based on existing methods and represent community consensus on how best to go about completing a task. For this reason, documenting the state of the art is an important first step.

Many wind plants are located in rolling or forested terrain or in areas where wind has strong diurnal and seasonal characteristics. These conditions are often described as "complex flow." These flow conditions are associated with wind characteristics that may cause wind measurements from cup anemometers, sonic anemometers, and remote sensing by Doppler wind lidar to differ even when the lidar or cups are installed and operated according to relevant industry standards such as International Electrotechnical Commission (IEC) 61400-12-1 (2005) or number 15 from the IEA's Expert Group Study on Recommended Practices (shortened to RP15; Clifton et al. 2013). Effects may include a persistent difference in the wind characteristics measured by one device compared to another, indicating a bias in one or both instruments. Or, the data from one device may show a variation or scatter in measurements relative to the other when measuring the same wind characteristics, indicating different measurement uncertainties and sensitivities with respect to significant environmental variables.

This report contains an overview of the state of the art for using Doppler wind lidar to measure complex flow wind fields - focusing on the mean flow over a 10-min period - for a range of wind energy applications. Complex flow is often a key influence resulting in the types of effect listed above.

This document describes how complex flow contributes to differences between measurements made by lidar and cup or sonic anemometers. Section 2 presents an introduction to the various lidar scan methods. Section 3 describes the challenge of measuring wind conditions in complex flow. Comparing the performance of lidar measurements with traditional measurements requires a documentation framework, which is composed of use cases, introduced in Section 4. In addition, there is a need to understand how wind lidar measurements compare to the traditional measures of wind speed obtained from cup anemometers. Section 5 discusses this validation process. Section 6 summarizes the major use cases currently represented by widespread industry experience. Preliminary recommendations for using lidar for wind energy applications in complex flow are given throughout the report.

\section{Disclaimer}

This document is not intended to endorse any one system, technology, or method over another. Lidar capabilities or configurations described in the text or tables or shown in figures are for illustration only and should not be taken as indicative of any particular device, nor of the actual capabilities of any device. The performance of a lidar and the availability of data may change 
with time and location depending on a range of internal and external factors, and decisions made during post processing of the lidar data.

Because this document cannot (and does not attempt to) capture all of the nuances of lidar measurement in complex flow, users interested in using lidar for measurements in complex flow are therefore strongly encouraged to work with their current or prospective supplier and a knowledgeable subject matter expert before deploying lidar for measurements in complex flow conditions. 


\section{Using Doppler Wind Lidar to Measure Wind Fields}

Doppler wind lidar remotely measures winds by emitting a laser beam that is reflected from aerosol particles in the atmosphere that are entrained with the wind. The backscattered light is Doppler-shifted by the motion of the aerosol particles in the direction of the line of sight. This Doppler shift can be used to estimate the speed of the particles. Because those particles are of the order of $1 \mu \mathrm{m}$ in size, they are assumed to act as tracers and thus move at the same speed as the wind. Figure 1 is a schematic of a basic Doppler wind lidar system.

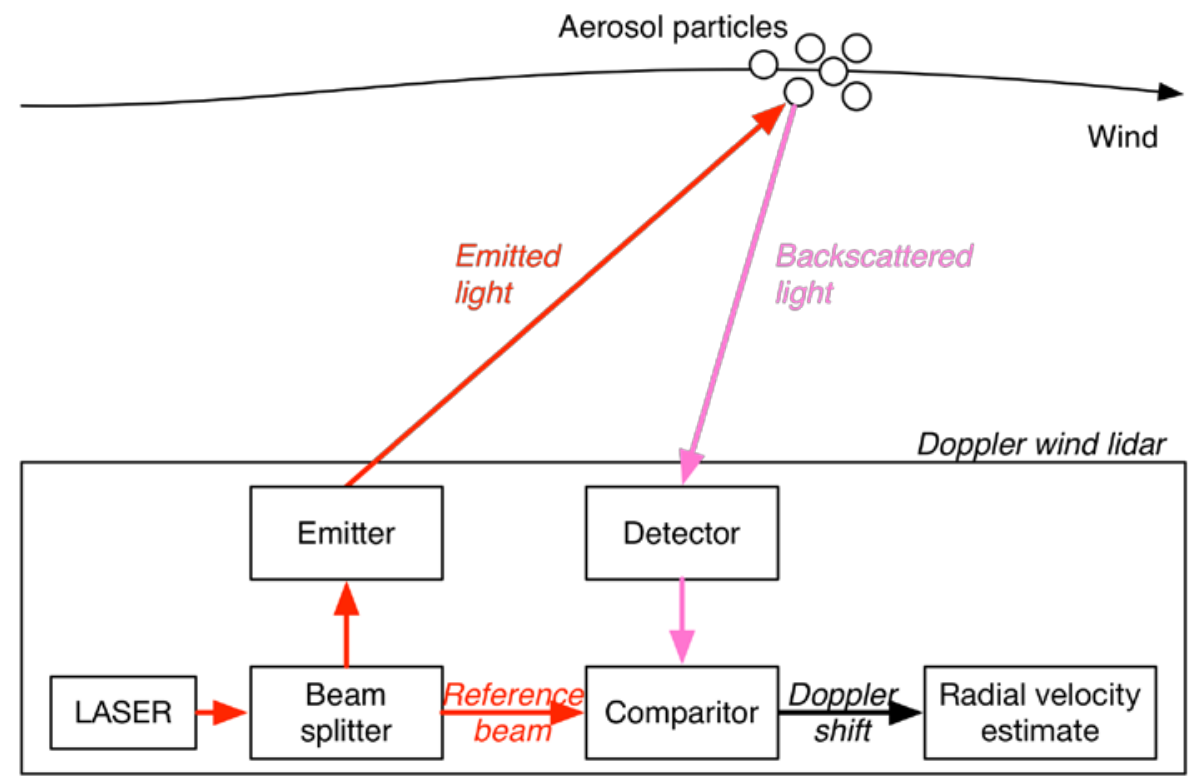

Figure 1. Schematic representation of a Doppler wind lidar system

In Figure 1, the angle between the emitted light and the backscattered light has been exaggerated. Usually Doppler wind lidar optics are designed so that the backscattered light is received through the same system that controls the orientation of the outgoing beam.

Typically a lidar scans its beam through a sequence of beam orientations, defined in terms of their azimuth angle $\theta$ and elevation angle $\varphi$. The orientation of the lines of sight relative to the wind direction in the probe volume determines the magnitude of the projection of the wind velocity vector onto the line of sight. As a result, this measurement yields a radial velocity (Figure 2).

The region where the radial velocity is acquired is termed the probe and has a characteristic probe length along which radial velocities are measured. Because the beam has a finite width, the radial measurement is made in a probe volume. The volume within which these individual probe volumes are distributed for the purposes of a measurement of one or more wind parameters is termed the measurement volume. The measurement volume is defined by the scan geometry, which is the arrangement of lines of sight along which lidar emissions occur.

Several radial velocity measurements can be combined and analyzed using assumptions about the flow properties. Wind parameters are typically extracted from the radial velocity data acquired during each individual scan, but can also be built up from longer time series. Some 
assumptions allow the wind in the measurement volume to be quantified; others are more qualitative. The aim of most of these methods is to understand the wind field, which is the spatial variation of the horizontal and vertical wind speeds, along with the wind direction. These could be in a vertical profile or over an area. Point values of the wind speed and direction are termed wind vectors.

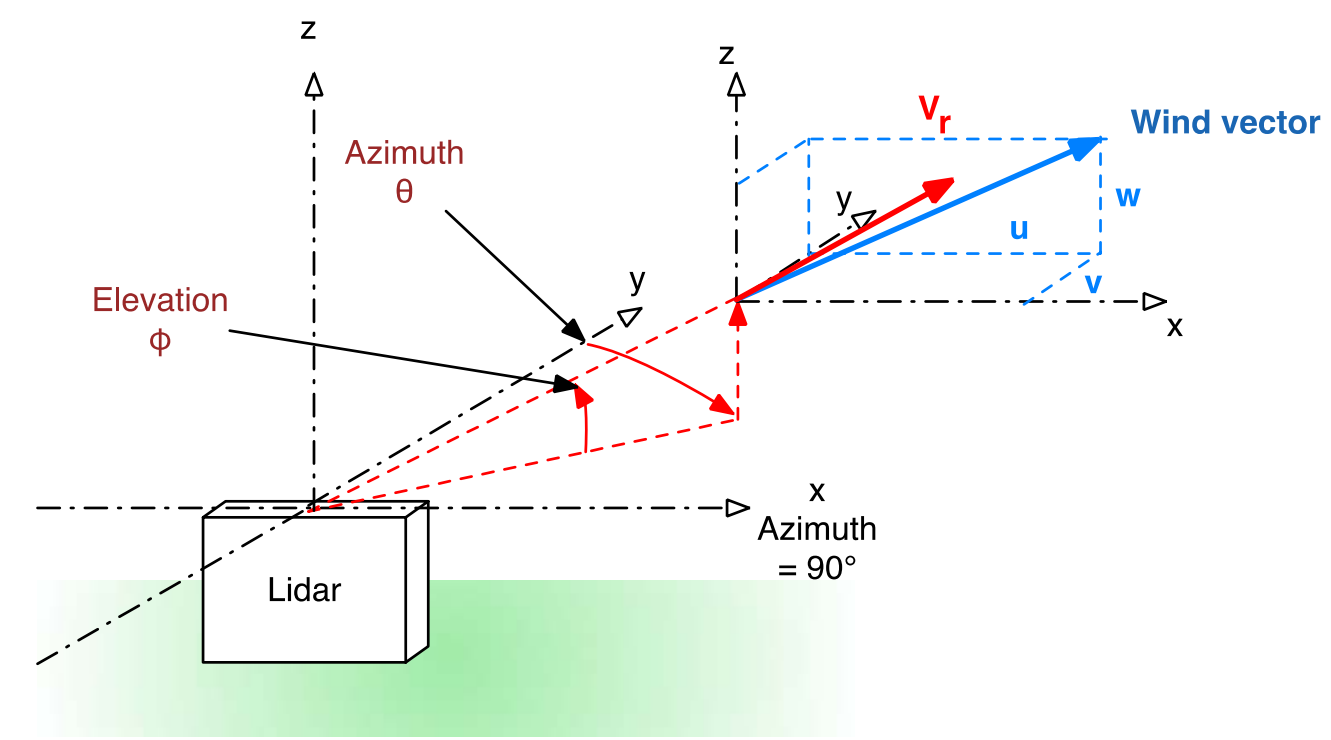

Figure 2. Illustration of the relationship between the wind vector and the radial velocity observed by a lidar

\subsection{Scan Geometry Categories}

Scan geometries can be categorized according to the number of units involved in the measurement:

- Scan geometries in which radial velocities are acquired relative to a single device location are termed single lidar.

- Scan geometries in which radial velocities are acquired relative to two or more device locations are termed multi-lidar.

Most Doppler wind lidar measurements are made using single lidar units; multi-lidar measurements are still the subject of much research and development. Both single and multilidar measurements are considered in this report.

Scan geometries can also be categorized according to their number of degrees of freedom:

- A simple scan geometry entails variation in beam orientation in a single degree of freedom.

- A compound scan geometry includes several simple scan geometries carried out in a sequence. These scans require lidar systems that have the ability to point the emitted light in arbitrary directions from the lidar. 
- A complex scan geometry has several degrees of freedom, varying both azimuth and elevation angles. As with compound scans, these require complex lidar systems.

A further degree of freedom is the radial distance from the lidar device to the probe volume. This distance can be set by observing the time of flight of a lidar pulse (for pulsed lidar systems) or by adjusting the focus of the optics (in the case of a continuous wave system).

Some examples of different scan geometries and data processing techniques are shown in Figure 3 and explained in more detail in the following sections.

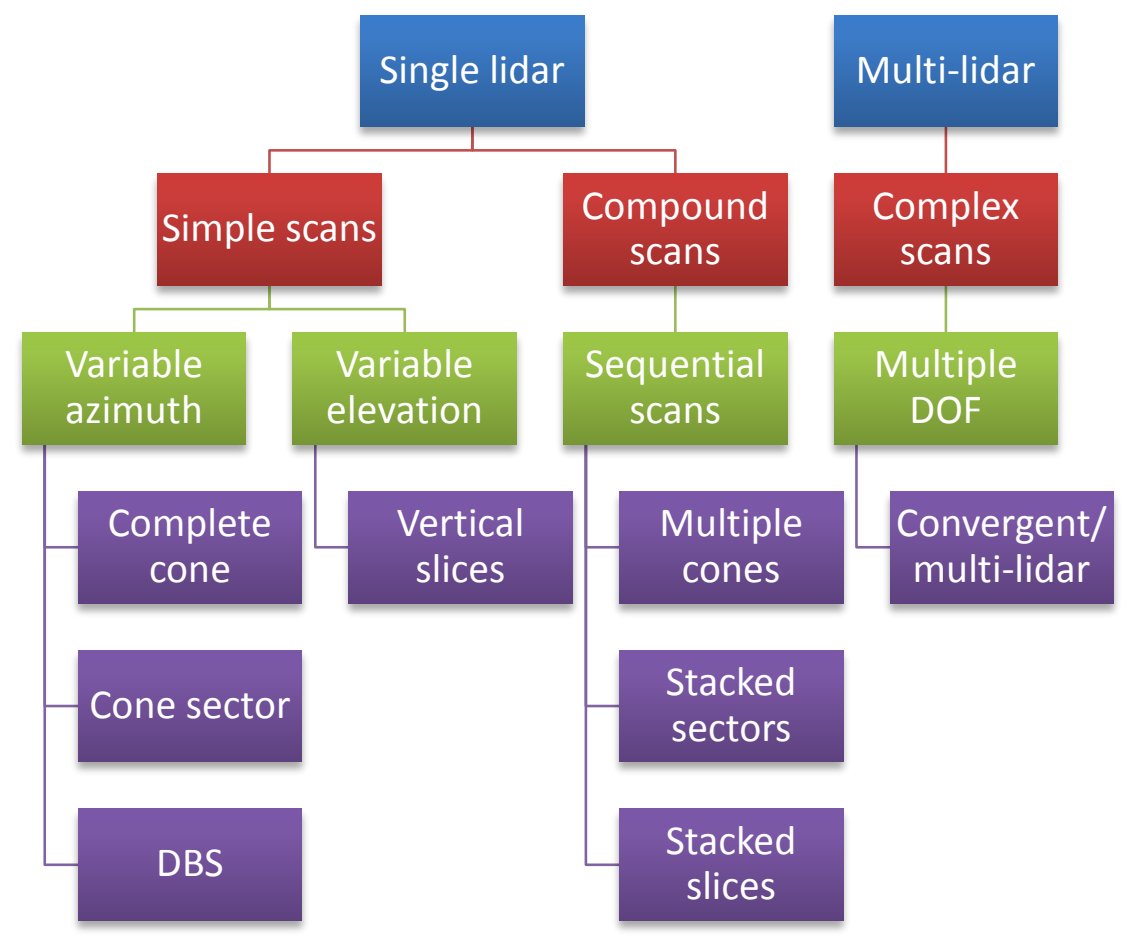

Figure 3. Different categories of wind lidar and associated scan geometries

\subsection{Scan Geometries Using Single Lidar}

Single lidar measurements acquire radial velocity measurements relative to a single device location.

\subsubsection{Simple Scans}

Simple scan geometries include, but are not limited to, complete cone, cone sector, and vertical slice scans.

Complete cone scans use an inverted cone scan geometry in which the elevation angle of the line of sight along which lidar emissions are directed is fixed and the azimuth angle is scanned between a number of positions spanning the full 360 degrees $\left(^{\circ}\right)$ of azimuth variability (Figure 4 and Figure 5). In a uniform flow field, the radial velocity measured by a lidar follows a sinusoidal curve with respect to azimuth, with the maximum in the sinusoid reached when the line of sight of the lidar is aligned with the mean wind direction. This knowledge is the basis of most wind speed and direction retrievals from conical-scan lidars. 
Two common approaches to measuring line-of-sight wind speeds and converting the data into wind vectors are conical scans analyzed with the velocity-azimuth-display (VAD) and Doppler beam swinging (DBS) methods. VAD is a method of analyzing data from a complete conical scan whereby many closely spaced azimuthal points may be sampled by the lidar (Figure 4), and the data are used to estimate the wind speed at each height using a statistical fitting method described in Lhermitte (1966) and Browning and Wexler (1968). In contrast, in the DBS method the lidar beam is swung from north to west to south to east (and may also include a vertical beam) (Figure 5), and the data can be used to calculate the wind speed analytically at each measurement height. Both the VAD and DBS approaches require only a single degree of freedom to the lidar beam (if the vertical beam is not used in the DBS pattern), and the pattern repeats regularly. They are thus well suited to dedicated lidar units, and so conical scans form the basis of most vertically profiling lidar use cases implemented in the wind energy industry and are deployed to replace and replicate meteorological (met) masts.

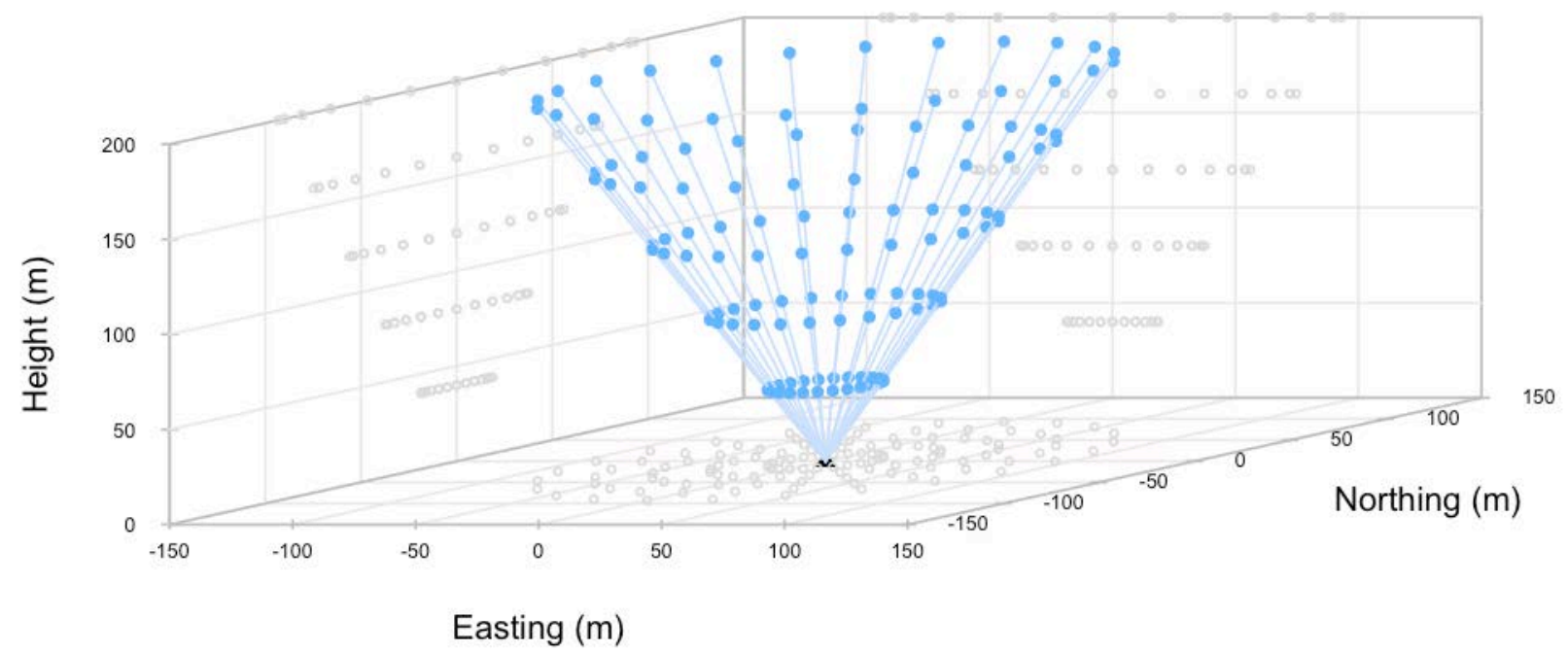

Figure 4. Visualization of measurement points in a conical scan

The lidar is shown by the black triangle. The round blue points indicate the nominal measurement locations associated with the probe and are shown projected onto the axes as grey points. In this case the angle from vertical is $25^{\circ}$, and the measurements are made every $15^{\circ}$ around the azimuth.

Measurements are spaced $40 \mathrm{~m}$ apart vertically. 


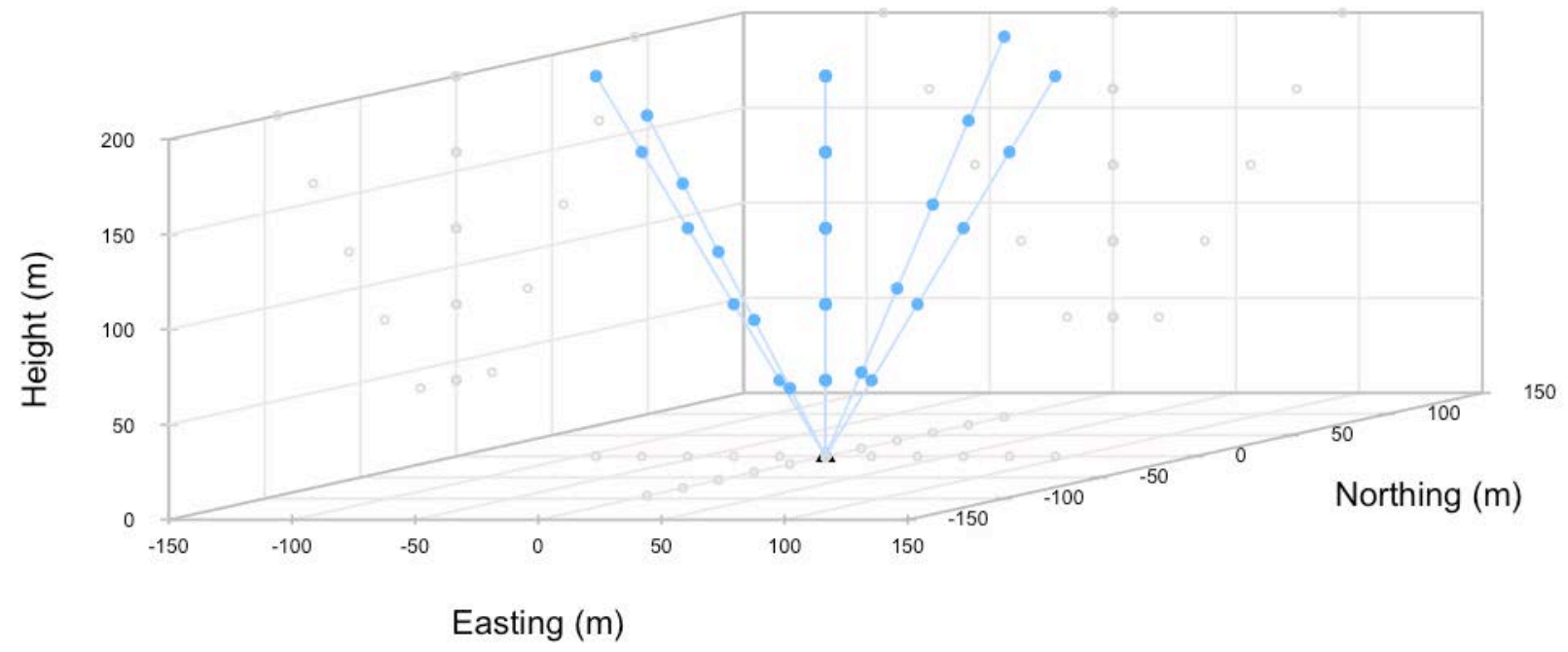

Figure 5. Visualization of measurement points in a DBS scan

The lidar is shown by the black triangle. The round points are the nominal measurement locations associated with the probe and are shown projected onto the axes as grey points. In this case the angle from vertical is $25^{\circ}$ and $0^{\circ}$, and the measurements are made every $90^{\circ}$ around the azimuth.

Measurements are spaced $40 \mathrm{~m}$ apart vertically.

Conical sector scans sweep a range of azimuths (but not the full cone) while maintaining a fixed elevation angle (Figure 6). These are also known as plan-position-indicator, or PPI, scans. A conical sector scan is typically densely sampled in the azimuthal direction because the objective is usually to visualize and map the flow in detail. As a result, high spatial resolution is required, which is achieved at the expense of time resolution. The duration of a conical sector scan may be tens of seconds or even minutes.

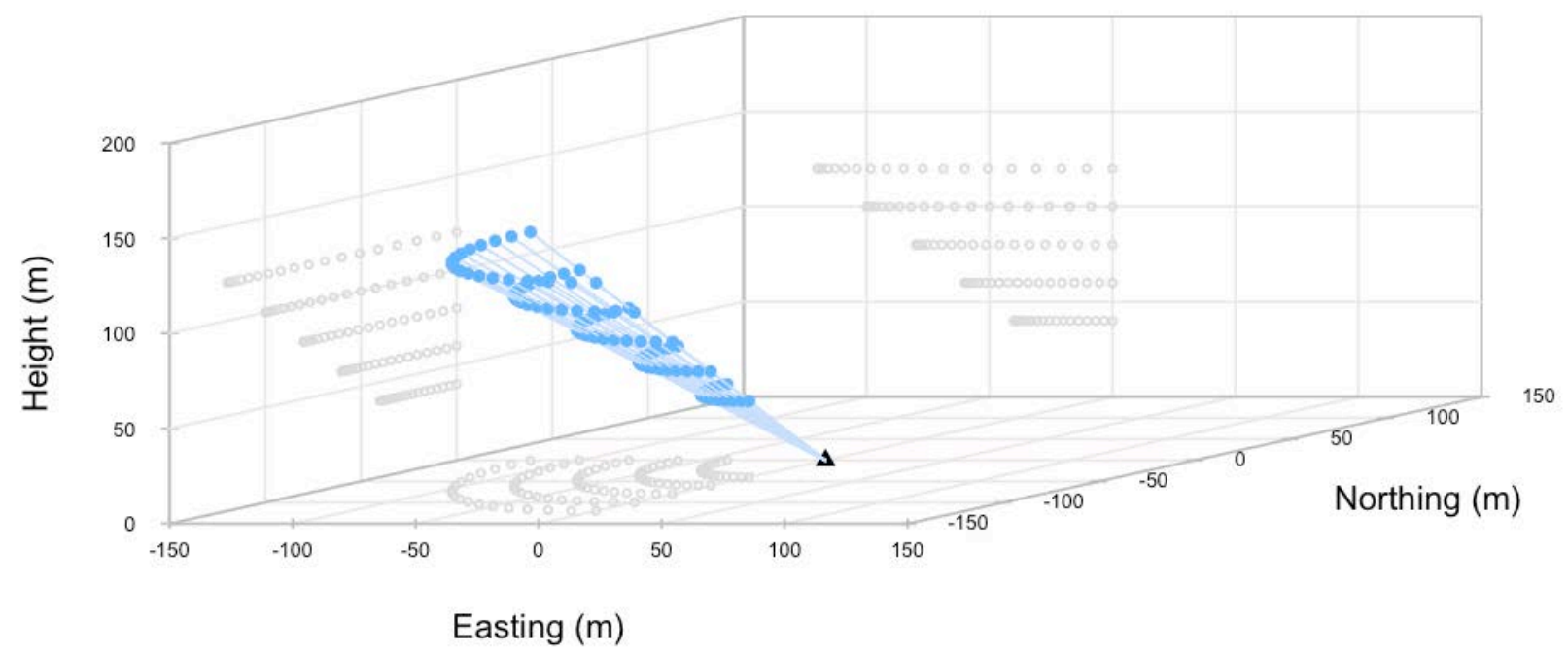

Figure 6. Visualization of measurement points in a conical sector scan

The lidar is shown by the black triangle. The round blue points are the nominal measurement locations associated with the probe and are shown projected on to the axes as grey points. In this case the angle from horizontal is $15^{\circ}$, and the measurements are made every $5^{\circ}$ across a $90^{\circ}$ azimuth arc.

Measurements are spaced $20 \mathrm{~m}$ apart vertically. 
Conical sector scans differ from other scans in that the lidar is not limited to acquiring measurements in the volume immediately above the device. For example, a low elevation angle can be used to measure horizontally far from the lidar. Typical ranges of azimuth angle are $90^{\circ}$, $60^{\circ}$, and $45^{\circ}$, with $30^{\circ}$ of azimuth being swept when the target measurement volume is particularly distant (Wang et al. 2015). However, if the range of azimuth angles is less than $30^{\circ}$, the variation in radial velocity resulting from turbulent fluctuations in the wind can be greater than that imposed by varying the orientation of the line of sight with respect to the wind direction, and so azimuth ranges of $30^{\circ}$ or greater are usually adopted.

An arc scan is similar to a conical scan, but uses data from a single range gate to sweep along an arc rather than a sector of a cone. Data can then be analyzed using the VAD fitting method to extract wind parameters.

Scans can also be made where the beam is swept through a vertical slice by varying the elevation angle but not the azimuth angle (Figure 7). These scans are also known as range-height-indicator (RHI) scans. This scan geometry may be used to look at details in the flow in the cross-sectional surface sampled by the scan (see Section 6.7).

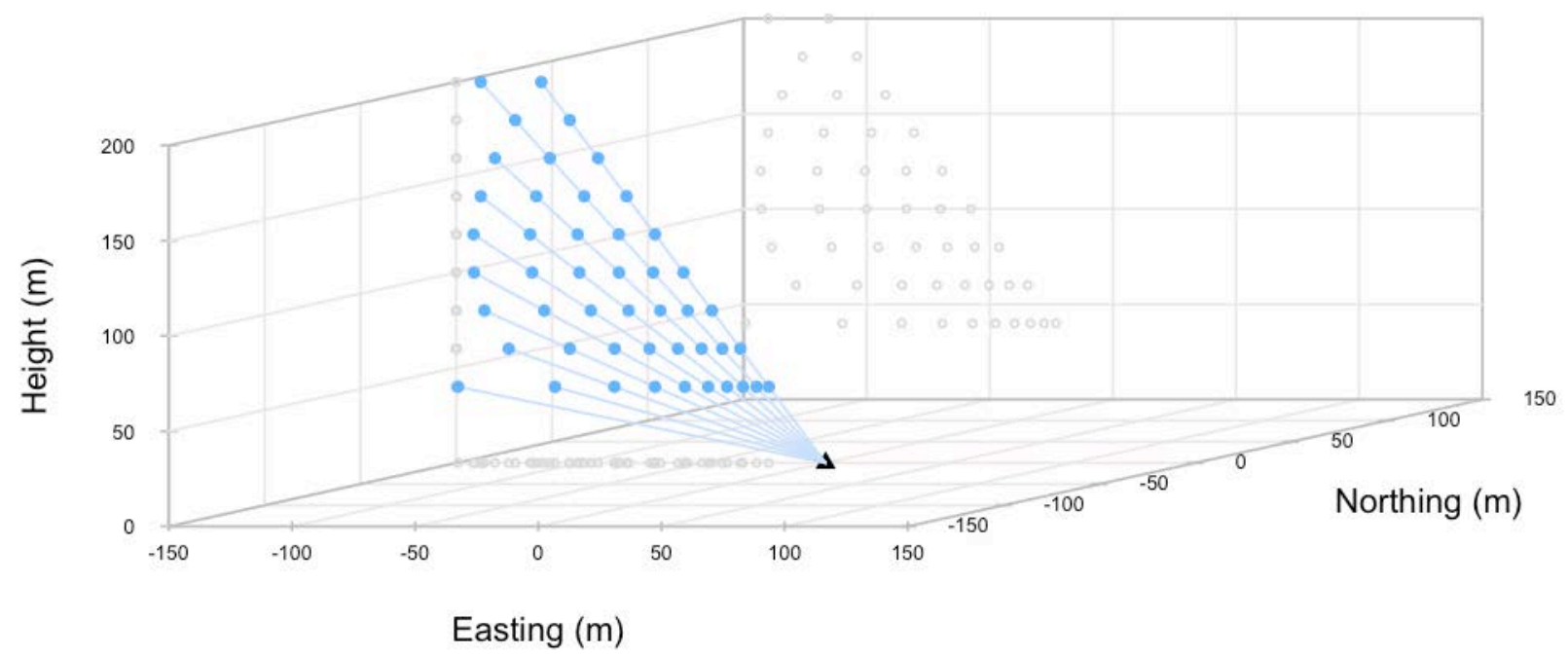

Figure 7. Visualization of measurement points in a vertical slice

The lidar is shown by the black triangle. The round blue points indicate the nominal measurement locations associated with the probe and are shown projected onto the axes as grey points. In this case the angle from vertical is from $0^{\circ}$ to $60^{\circ}$, and the measurements are made every $5^{\circ}$. Measurements are spaced $20 \mathrm{~m}$ apart vertically rather than uniformly along the radial direction, which might be more common in practice. Points outside the axes have been removed.

Challenges with sampling a wind field include that it varies with time due to phenomena such as turbulence and points within the wind field are not sampled simultaneously by the probe. These factors can lead to a situation where variation in radial velocity with azimuth in a scan is less than the variation introduced by turbulence, which makes wind field reconstruction difficult or impossible. This is sometimes known as turbulent decorrelation. It can be overcome by averaging the measurement over multiple iterations of the scan geometry. Considering multiple adjacent probe volumes along the lines of sight is an additional option. Probe volumes along a single line of sight are sampled simultaneously by a pulsed lidar system and can be fitted using a 
model that describes the variation in radial velocity with the location and orientation of the probe volumes in which they are measured to a "ribbon" instead of an arc of data.

\subsubsection{Compound Scans}

Compound scans include more degrees of freedom and are typically made up of a sequence of simple scans. For example,

- A compound scan geometry may include beams with a single azimuth angle but different elevation angles to survey a vertical surface to acquire detailed information about wind shear, flow recirculation, and other beams with a single elevation angle but different azimuth angles to acquire information about wind direction. The arc scan or conical sector scan would allow wind direction to be assessed to ascertain how the wind field is projected onto the surface assessed using the vertical slice. Compound scans can also include a conical scan measurement coupled with a vertical beam.

- A compound conical scan can include two (or more) conical scans with distinct cone elevation angles, each optimally assessing the shear profile within a different range of heights (Figure 8). These techniques can allow pulsed lidar devices to measure down to ground level. This is useful for performance verification against short reference met masts.

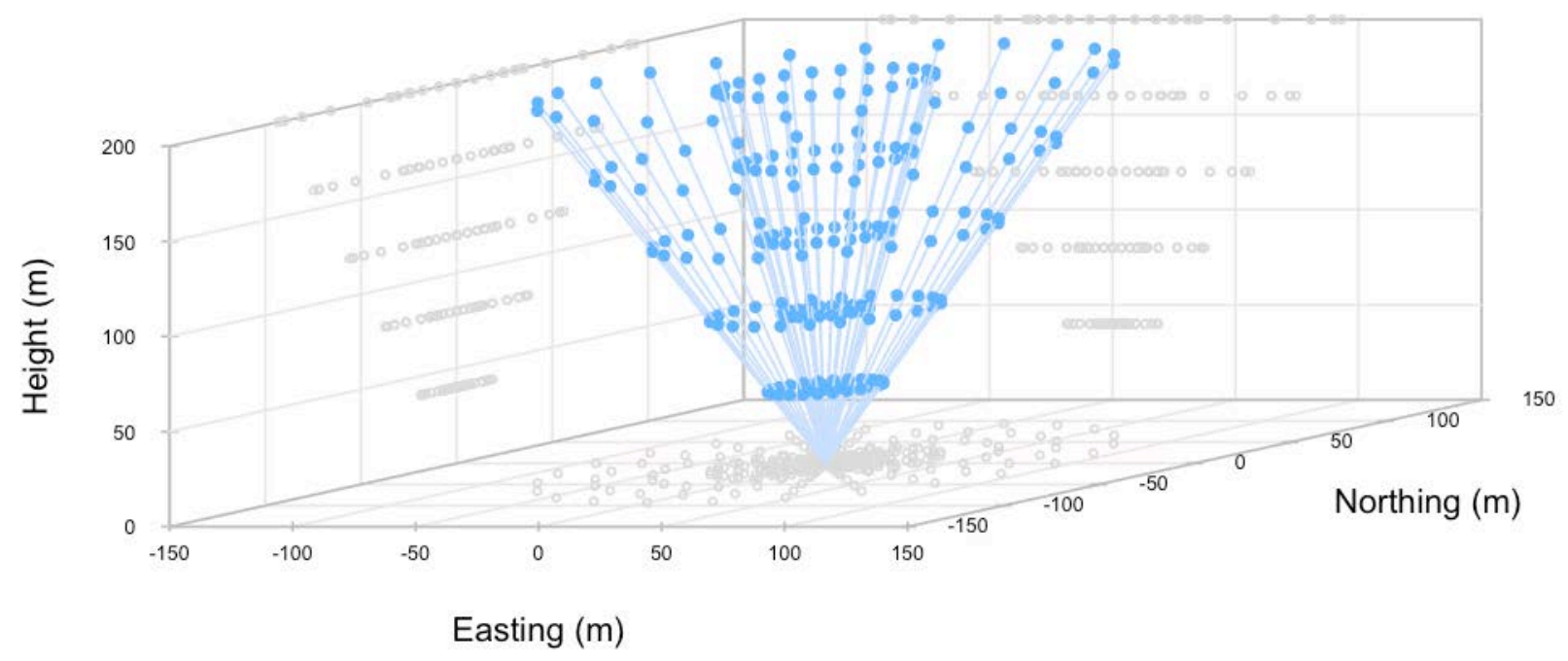

Figure 8. Visualization of measurement points in a compound conical scan

The lidar is shown by the black triangle. The round blue points indicate the nominal measurement locations associated with the probe and are shown projected on to the axes as grey points. In this case the angles from vertical are $10^{\circ}$ and $25^{\circ}$, and the measurements are made every $15^{\circ}$ around the azimuth. Measurements are spaced $40 \mathrm{~m}$ apart vertically.

A stacked conical sector scan includes several conical sector scans at different elevation angles to survey a three-dimensional volume in space. This type of scan can be used to assess the shear profile over a wide area. A stacked arc scan using the same concept can be used to assess the shear profile in a location horizontally distant from the location of the device. 


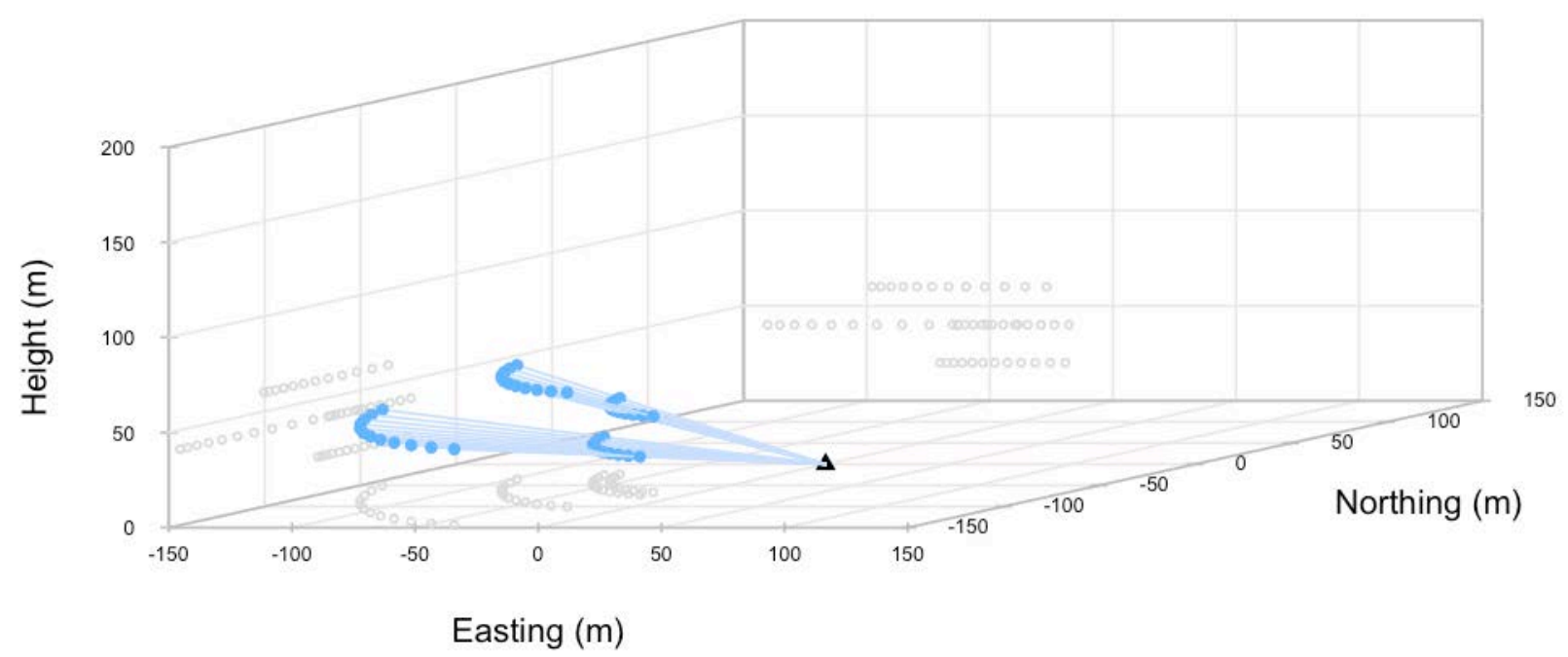

Figure 9. Visualization of measurement points in a stacked conical sector scan

The lidar is shown by the black triangle. The round blue points indicate the nominal measurement locations associated with the probe and are shown projected onto the axes as grey points. In this case the angles from vertical are $15^{\circ}$ and $30^{\circ}$, and the measurements are made in an arc $60^{\circ}$ wide at points $5^{\circ}$ apart around the azimuth. Measurements are spaced $20 \mathrm{~m}$ apart vertically and start at $20 \mathrm{~m}$ above ground. Points outside the axes have been removed.

\subsection{Multi-Lidar Scan Geometries}

The scan geometries described up to now are divergent in that the beams diverge from a single device. Convergent scan geometries involve multiple devices and beams from each that converge on a single point in space. Convergent scan geometries include configurations referred to as dual and triple Doppler, multi-lidar or multiple lidar, windscanner, and crossed vertical slices (crossed RHI, or XRHI). Depending on the circumstances and the application, the advantages of convergent scan geometries can include the following:

- High time resolution: The wind vector is retrieved by sampling the same volume simultaneously from several different directions rather than by looking in multiple directions from a single location. This means that there is no time spent scanning to build up the data required to retrieve the wind vector, and so the temporal resolution increases compared to scanning systems. This can be beneficial in retrieving flow statistics; tests indicate that turbulence intensity measurements from convergent scan geometries compare well to data from reference met towers (Mikkelsen et al. 2008).

- Complex terrain: Some data extraction algorithms are based on a model of a horizontally homogeneous flow. This means that each probe volume at a given height is assumed to sample the same flow. In this case, the variation in radial velocity can be attributed entirely to the change in the orientation of the beam. When this assumption is not valid because of, for example, terrain-induced flow distortion, atmospheric instability, convective conditions, or the influence of a wind turbine or another obstacle on the flow, a bias will result unless another method is used. Under these circumstances, convergent scan geometries have an advantage because the technique collapses the measurement volume and so limits the extent to which different probe volumes correspond to different wind conditions in violation of the assumption of homogeneity. The measurement 
volume corresponds to the region in which the probe volumes from the several devices intersect and overlap. If the size of this region is significantly less than the length scale associated with complex wind structures and heterogeneities, unambiguous wind velocity vector information can be acquired. 


\section{Recognizing Complex Flow}

In a meteorological context, a complex flow is defined as a flow that shows strong spatial and temporal variability. This is also called heterogeneous flow.

\subsection{Causes of Complex Flow}

Complex flow is caused by the interaction of terrain, surface roughness, local and regional meteorology, and the presence of obstacles in the flow. Here are some examples:

- Where slope angles change more than a few degrees over a short distance, such as over ridges, in valleys, or in rolling hills, the flow near the ground may be inhomogeneous or even separate from the ground, causing local deceleration or recirculation. In addition, winds behind large objects or terrain features such as ridges, mountains, or forests (at their downwind edges) may reverse locally, leading to recirculating flow. That flow has very high wind speed gradients locally and can be unstable such that it moves or oscillates over time. Bingöl (2009) and Abiven et al. (2011) present examples.

- Complex terrain can be specifically identified using the definitions for turbine locations given in IEC 61400-12-1 (2005), and from the terrain types used in the European Wind Atlas (Troen and Petersen 1989). Because remote sensing methods measure winds at or near turbine hub heights, they are subject to the same considerations of flow interaction with terrain.

- Some practitioners have developed their own rules of thumb to help identify complex terrain from terrain complexity metrics such as the ruggedness index, or RIX, found in WAsP, a popular resource assessment tool. The ruggedness index correlates with errors in the flow modeling, and thus may help identify areas of complex flow. A review of different terrain complexity metrics can be found in Clive (2013).

- Flow modeling has been suggested as a way to check the differences associated with different combinations of measurement methods and flow conditions before measurements start (Klaas et al. [forthcoming]).

- Variation in land cover or vegetation upwind of the measurement point might cause strong horizontal and vertical variations in wind speed. The upwind fetch distance that affects the measurement point may be up to 100 times the height of the measurements, depending on roughness and stability.

- Forested land leads to increased wind shear and an increase in turbulence intensity, especially at measurement heights close to the height of the trees.

- Obstacles such as wind turbines can shed wakes that have very high spatial and temporal variability. See, for example, Lundquist et al. (2015).

- Meteorological features such as jets from mountain passes, fronts, or the passage of transient features through the measurement domain may all cause flow heterogeneity. Strong diurnal cycles of wind direction or surface heating may also cause flow characteristics to differ by direction or time of day. 
Note that complex flow is distinct from flow over complex terrain, but that complex terrain suggests the possibility for complex flow. In addition, complex flow is not continuously present. Flow characteristics may differ depending on wind direction, time of day, and measurement height.

Experience shows that complex flow can cause a difference between the wind vector measured by a lidar, and that measured by a cup or sonic anemometer at the same location. Although the cup or sonic anemometer device might also not be performing perfectly in the complex flow, it is essential to know why there are differences between the lidar and reference, and to minimize or understand those differences. This is particularly important as the cup or sonic anemometer's measurements can be validated under controlled conditions in a test laboratory that conforms to national standards, and as a result they are used as reference instruments for comparison with lidar measurements. The ability to reconcile the lidar measurements with point measurements may reduce the uncertainty that is later estimated for the lidar measurements.

\subsection{Effects of Complex Flow on Cup or Sonic Anemometers}

Although cup and sonic anemometers yield the reference data to which lidar measurements must be compared (so that the accuracy of lidar measurements may be traced to national standards and are acceptable within the wind energy industry), these reference instruments themselves are not immune to the effects of complex flow. These effects come from several main sources, including the following:

- Vertical components of turbulence

- Sustained off-horizontal or inclined inflow

- Effects of mountings, including vortex shedding from housings, wakes, or towers.

These and other effects are discussed in many documents, with some investigators suggesting that wind speed measurements may show as much as $2 \%$ uncertainty as a result of complex flow (see, for example, Papadopoulos et al. 2001).

\subsection{Effects of Complex Flow on Doppler Wind Lidar}

The different causes of complex flow that were listed in Section 3.1 have differing effects on lidar measurements. These effects depend to a degree on the method used to estimate the wind velocity vector from raw lidar measurements of radial velocities relative to the lidar location(s) along multiple lines of sight.

Single Doppler wind lidars measure the line-of-sight radial velocity using many different azimuth angles scanned from a single point. These lidar measurements can be converted into a wind vector by assuming that the flow within the measurement volume is homogeneous. A crucial difference between scans from a single lidar and data obtained from cup or sonic anemometers is that the wind vector derived from the lidar is a volume-averaged wind vector; cup anemometers measure a scalar wind speed and sonic anemometers measure a wind vector at a single point.

Spatially inhomogeneous flow can lead to a difference between a lidar-derived wind vector and a point measurement in that volume. This can arise for several reasons, including the following: 
- Flows over ridgelines, around terrain, or within turbine wakes may have different vertical components on each side of the measurement volume, causing an error in the estimated velocity. A detailed explanation of this problem is given in Bingöl et al. (2009).

- Winds at the same height above ground may also accelerate or decelerate because of terrain. If a conical scan measurement were made in a location that experiences acceleration and deceleration (e.g., over a ridgeline), the measurement would average these flows.

- If variation in wind speed with height is significant, the probe length and the weighting function of the data retrieved within that volume (which may be uniform or some other function, depending on the lidar technology) may lead to an over- or underestimation of the wind speed, compared to the results from an anemometer at the nominal measurement height, as discussed in Clive (2008).

- A high range of shear or turbulence intensity may cause changes in lidar accuracy that vary according to flow direction or by day or season.

Consequently, changing the lidar sampling method and the data analysis methods will change the bias and uncertainty between lidar data and point measurements. It is important, then, that the differences are estimated before the measurement campaign starts. Similarly, the end users of the data should agree that the uncertainty and bias in the data are appropriate for their application.

This document, and in particular the description of use cases, may contribute to future progress in defining requirements relating to the levels of accuracy and reliability necessary for formal certification for specific applications. However the definition of the necessary lidar performance acceptance criteria is outside the scope of this report.

\subsection{A Practical Definition of Complex Flow}

The previous discussion shows that there are several potential indicators for complex flow:

- Complex terrain according to IEC 61400-1 (2010) and IEC 61400-12-1 (2005) standards, the European Wind Atlas (Troen and Petersen 1989), or from practitioners' experience (quantified using other terrain complexity metrics)

- Changes in upwind surface roughness or the presence of trees, which may cause flow heterogeneity

- The presence of human-built obstacles or natural features that may cause wakes in the measurement volume

- Local meteorology or terrain that may cause spatial heterogeneity within the lidar measurement volume

- Comparison of the lidar measurements with cup or sonic anemometer measurements may show bias or uncertainties that exceed the expected combined lidar and point measurement uncertainty from standards such as the proposed IEC 61400-12-1 Ed. 2 CD (2015). This difference indicates that the flow reconstruction method and post-processing does not truly capture the effect of the flow on the measurements.

Figure 10 shows the five major indicators of complex flow. 


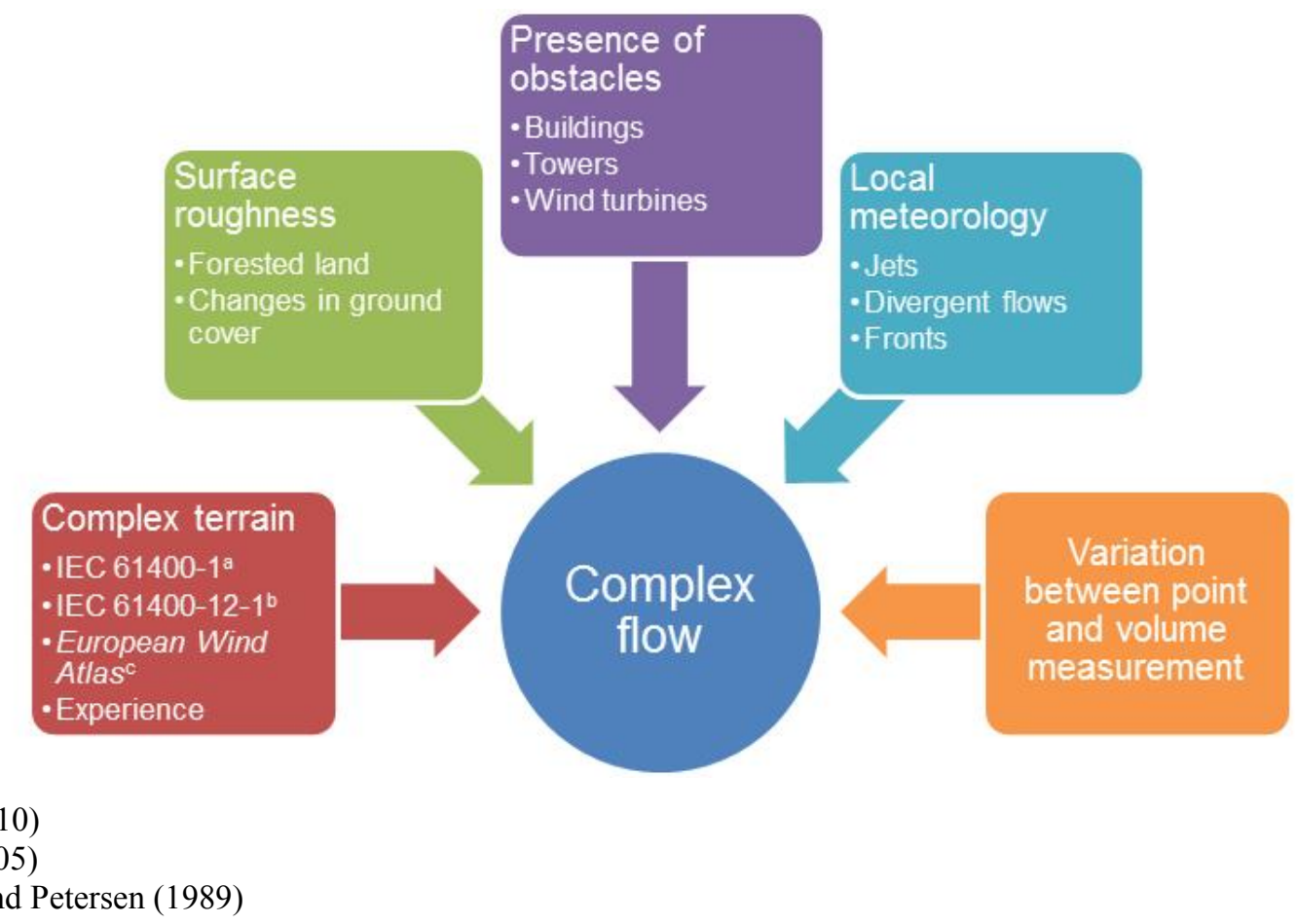

${ }^{\mathrm{a}} \operatorname{IEC}(2010)$

${ }^{\mathrm{b}}$ IEC (2005)

${ }^{\mathrm{c}}$ Troen and Petersen (1989)

Figure 10. Indicators of complex flow that may be important for comparisons of lidar and point measurements

Effort is evidently needed to produce a clear and objective set of complex flow indicators instead of the qualitative indicators shown in Figure 10, but that is outside the scope of this report.

Preliminary recommendation: Define complex flow based on terrain or meteorological conditions. Flow should be considered potentially complex if any of the indicators shown in Figure 10 are present. 


\section{Documenting the State of the Art Through Use Cases}

The concept of the "use case" is borrowed from systems engineering to document the wide variety of ways in which Doppler wind lidar is used to obtain wind data. The use case is how a set of tools or methods is applied in a set of circumstance to achieve a defined goal.

In deploying Doppler wind lidar, a use case is a combination of the data needs, the situation in which the measurements are made, and the measurement method:

- The data needs are the specific information that the lidar is being used to deliver. Data needs impose certain requirements on the use case. Examples include, but are not limited to:

○ Wind speed profiles

○ Turbulence profiles

- Wake characterization.

- The situation is the combination of flow conditions and other external factors in which the lidar will have to operate. Several examples were given in Section 3, and some others are listed here:

○ Complex flow

○ Complex terrain

- Flows within a wind plant

- Flows between wind plants.

- The method is the approach or procedure that is applied to ensure a valid use of the Doppler wind lidar and data. Each method will have different pros and cons when applied for a specific use. The method could be applied to the lidar measurement, to the data analysis, or to both. Common methods include:

- Conical scanning methods, including modifications to data collection such as a vertical beam or modifications to the data analysis

- Flow models to convert from volumetric scans to point values

- Dual or triple lidar methods

○ Postprocessing using flow models or statistics.

Typically the data needs and the situation are imposed on users, but they can freely choose the method to use. The choice of method may be constrained if the user owns a device and wants to use that instead of buying or renting a new one. The methods that are possible with that device, however, may not be appropriate for the situation. The application of the same measurement method in different situations will result in different levels of performance. The use case is valid if the achievable performance, in terms of accuracy, is sufficient to fulfil the data needs. The use case is optimal if the method selected to make the measurements represents the best performance possible with respect to the data requirements under the circumstances. 
It is important to recognize that there are a limited number of valid combinations of data requirements, situations, and methods that can form a use case. For example, if an inappropriate method is chosen for a certain situation, the data needs will not be met because the output data will be biased (Figure 11).

\section{Data requirements}

- The specific information that this measurement should deliver

\section{Situation}

- The flow and external conditions in which the lidar must function

\section{Method}

- The measurement method that is valid in this situation

\section{Use case}

- The combination of data requirements, situation, and method

Figure 11. How the data requirements, the conditions, and methods relate to each other and combine to define a specific lidar use case

This report describes the different use cases instead of just different methods. This approach is taken to ensure that the interrelations among the data needs, situations, and methods are captured. Each use case is documented separately in summary tables in Section 6. 


\section{Validating the Performance of Lidar in Complex Flow}

When using Doppler wind lidar in complex flows, it is important to understand the performance of the Doppler wind lidar with respect to a well-defined reference measurement. In the wind energy industry, cup anemometers mounted on a met mast or tall tower in a manner that is compliant with IEC standards are usually accepted as the reference measurement. The process of quantifying performance relative to the reference is known as validation.

Validation can be carried out by direct comparison of lidar measurements with met tower measurements of wind speed and direction. However, it was shown in Section 2 and Section 3 that the accuracy of wind speed and direction from the lidar may be dependent on the measurement method and flow conditions. Therefore, validating a measurement method in one set of conditions and then using it in different conditions may result in unanticipated discrepancies.

Preliminary recommendation: Because there is a clear relationship between the data needs, the method used, and the situation in which the Doppler wind lidar measurement is made, each use case should be validated individually.

\subsection{Transferring Experience from Site to Site}

A difficulty with the use of lidar for measurements in complex flow situations is in understanding the sensitivity of the use case to the measurement method and site conditions. As an example, consider a comparison of a lidar measuring flow using one of the use cases described in Section 6 and a cup anemometer in that flow. Following IEC 61400-12-1 Ed. 2, the standard deviation of the difference between the cup anemometer and lidar is considered to be the square root of the sum of the squares of (1) the uncertainty of the cup measurements; (2) the uncertainty resulting from the verification test; and (3) the uncertainty resulting from the classification, mounting effects, and heterogeneous flow. Therefore, the uncertainty estimate found in one test cannot be applied at a new site without understanding the causes of uncertainty, knowing the relevant conditions at the new site, and having a way to estimate the uncertainty from conditions at the new site.

The remote sensing classification method that is proposed in Annex L of the forthcoming IEC 61400-12-1 Ed. 2 standard may offer ways to develop uncertainty models that can be applied to different sites and flow conditions in response to the challenges listed above. The classification method can determine a lidar's sensitivity to external conditions (for example, shear or turbulence, and other factors). Therefore, if the terrain is similar at a new site, in terms of a suitable terrain characterization, and the same wind conditions (e.g., shear, turbulence, and other significant influences) are measured at the new site, it is possible to use the uncertainty model from the test site with the data from the new site. If those data are not available for the new site, an uncertainty model cannot be used to assess performance at the new site.

Where there is no available model of lidar sensitivity, it may be appropriate to use triple lidar measurements to create a virtual reference anemometer (see Section 2.3, Mikkelsen et al. [2008], and Clive [2011 and 2009]), and validate the use case in situ through short-term measurement campaigns. Triple lidar systems may be well-suited to this validation role because of their small 
convergent sampling volumes compared to other scan geometries, which are thus closer to the measurement volume of cup anemometers than other remote sensing devices (but still much larger), and do not rely on the assumption of flow homogeneity. In particular, the measurement volume is smaller than the length scale over which the flow inhomogeneities implicated in lidar bias occur.

Preliminary recommendation: Use cases should be validated in such a way that allows an uncertainty estimate specific to the deployment location:

- Validation measurements can be made at the deployment site or at a sufficiently similar reference site against reference devices. Validation measurements should surround or intersect the reference devices. Suitable reference devices include:

- Cup or sonic anemometers mounted on a met mast or met tower. Anemometers should be positioned so that they are within $1 \%$ of free stream wind speeds according to IEC 61400-12-1 Ed. 1 (IEC 2005). Anemometers should be IEC 61400-12-1 Ed. 1 (IEC 2005) Class 1 cup anemometers with a well-defined cosine response or calibrated three-dimensional sonic anemometers.

- Any other remote sensing method that has been validated and has a well-defined sensitivity to terrain, flow, or environmental conditions can be used.

- When validation measurements are made at a different site, the following factors apply:

- The range of turbulence, shear, and terrain complexity at the reference site should be similar to the expected range at the deployment site. Terrain complexity should be assessed using IEC 61400-12-1 Ed. 1 (IEC 2005) and any other relevant method.

- There should be a well-defined sensitivity to the situation-including terrain and flow - that can be used to estimate uncertainty at the deployment site. This may take the form of an uncertainty classification following the method proposed in IEC 61400-12-1 Ed. 2 CD (V) (2015).

- The uncertainty classification should be used to estimate the uncertainty of the measurements at the deployment site.

- The methods being validated should use identical measurement methods while they are being tested as well as at the deployment site, and the following criteria should be met:

- If a scanning lidar is to be verified, the elevation and distance to the reference wind speed measurement should be as close as possible to the distance from the lidar to the target measurements at the deployment site. The scan geometry should be the same during tests at the reference site and the deployment site.

- Averaging intervals for the met tower and wind lidar data should match.

- Data availability from the lidar and reference instrument within each averaging interval should be similar. If not, the impact of this difference should be assessed. 


\subsection{Lidar Certification}

It should be noted that validation is different from certification. Certification implies that a lidar is fit to be used for a specific application and would require demonstration of required levels of performance in relation to industry agreed acceptance criteria by an industry agreed procedure. Detailed procedures have been developed and agreed for classifying the accuracy and verifying the performance of lidars through open transparent processes and forums, for example, in IEC 61400-12-1 Ed. 2 CD (V) (2015). However, acceptance criteria that relate to lidar performance and define the required levels of performance necessary for certification have not been agreed upon through a similar process and are application specific and currently a matter of contract, convention, or convenience rather than formal conformance and certification. Therefore, no formal certification procedure currently exists for lidars.

It is hoped that the development of use cases and the accompanying documentation and experience, following the framework set out in this document, may support the eventual certification of lidar for some use cases.

\subsection{Future Developments in Validation}

The extended capability of lidar, when compared to the more limited capabilities of cup anemometry, results in the introduction and adoption of new measurement methods that do not have simple analogues in established practice. This introduces challenges that need to be addressed by measures such as, but not limited to, the development of this guidance. The challenges arise when:

- Validating the performance of lidar methods using conventional cup anemometry or other reference instruments with more limited capabilities, in particular when the lidar method itself has no simple met mast analogue for comparison and reference purposes, or provides datasets with no corresponding reference dataset for comparison due to the limitations of the reference instruments.

- Characterizing the measurement circumstances in sufficient detail that the validated performance can be:

- Understood with respect to the situation and conditions in which it is observed

- Anticipated in other similar situations described in a similar level of detail.

- Modifying wind energy assessment procedures to:

- Take advantage of new datasets made available by lidar methods to address issues previously neglected due to historic limitations in data acquisition

- Dispense with approximations that are conventionally adopted in established wind energy assessment procedures to accommodate an incompleteness of information about wind conditions that new lidar methods allow us to overcome and which therefore no longer need to be applied.

The validation of lidar performance in complex flow, in particular, the validation of performance in individual use cases connected with specific data requirements and situations, will form the basis for meeting these challenges. 
In order for wind energy assessment procedures to be modified in accordance with the third challenge listed above, it is necessary to ensure that the identification of specific data needs is not limited to those that have conventionally been fulfilled using more limited measurement techniques as this will artificially and unnecessarily restrict the data needs being addressed. Data needs should be identified with reference to the requirements of long term wind power project success in an outcome driven rather than a constraint driven manner: we should ask "what do we want to measure?" rather than "what can we measure?" first. Once data needs have been phrased with respect to desired project outcomes rather than perceived restrictions in data acquisition that may in fact no longer apply, the situation can be assessed and suitable methods selected to fulfill the needs. 


\section{Lidar Use Cases}

A variety of lidar use cases are documented in this section, employing the use case concept that was introduced in Section 4. The use cases are described in the text and tables in this section, along with pros, cons, validation options, and useful references. The following use cases are considered:

- Use cases based on conical scanning lidar

- Flow reconstruction from conical scans in homogenous flows

- Flow modeling to convert wind lidar measurements to point values

- Flow reconstruction from conical scans without assuming homogeneous flow

- Vertical beam use to reduce uncertainty in the vertical component

- Use of a smaller lidar sampling volume to reduce differences compared to cups

- Use of a short met mast to scale lidar measurements.

- Use cases based on scanning lidar

- Use of conical sector or slice scans to qualitatively identify flow features

- Flow reconstruction from conical sector or slice scans in complex flows

- Scanning lidar use for quantitative analysis of wakes

- Multiple lidar use to measure wind vectors.

These use cases are the most common for lidar in complex flow situations at the time of this writing. However, other use cases exist (see, for example, the use cases described in Clive [2015]), and other cases will become established over time as new data needs are identified by the wind industry, new methods are developed, or experience grows with existing methods. New use cases can be documented following the same use case protocol established here. If the requirements, situation, and method are documented adequately, that will enable repeatability, transferability, and consistent application of the use case, and a complete, robust, and unbiased uncertainty analysis. Similarly, existing use cases may be refined over time and the documentation and case studies in this document may be updated. 


\subsection{Flow Reconstruction from Conical Scans in Homogenous Flows}

Table 1 describes the standard use case for wind-profiling lidar of converting multiple radial velocity measurements into a wind vector.

Table 1. Flow Reconstruction from Conical Scans in Homogenous Flows

\begin{tabular}{|c|c|}
\hline Issue & Description \\
\hline Data needs & Flow vectors in a profile, over a plane, or in a volume \\
\hline Situation & Simple flows that do not exhibit curvature or heterogeneity \\
\hline \multirow[t]{3}{*}{ Method } & $\begin{array}{l}\text { If the wind field has components } u, v \text {, and } w \text {, and flow is homogenous, a lidar looking at } \\
\text { the wind field with an elevation } \phi \text { and azimuth } \theta \text { will measure a radial velocity } V_{r} \text {, where }\end{array}$ \\
\hline & $V_{r}=u \cdot \sin \theta \cos \phi+v \cdot \cos \theta \sin \phi+w \cdot \sin \phi$ \\
\hline & $\begin{array}{l}\text { To estimate the wind vector, multiple measurements of } V_{r} \text { are made at known range } \\
\text { gates (corresponding to specific heights above ground), elevation, and azimuth angles } \\
\text { in a conical scan. It is assumed that } u, v \text {, and } w \text { are only a function of height above the } \\
\text { lidar. A best fit is then used to find the values of } u, v \text {, and } w \text { that best predict the radial } \\
\text { velocity data at different heights. }\end{array}$ \\
\hline Pros & Works with any profiling lidar or a lidar capable of arbitrary scan geometry \\
\hline Cons & $\begin{array}{l}\text { Flow reconstruction assumes that the radial velocity measurements are representative } \\
\text { of the flow in the measurement domain and do not include distortions resulting from } \\
\text { wakes or other effects. Uncertainty increases, then, if the flow becomes heterogeneous } \\
\text { because of these effects (see Section } 3.2 \text { ). }\end{array}$ \\
\hline Validation & $\begin{array}{l}\text { Usually checked against a reference tower to give a bulk uncertainty estimate. Tower } \\
\text { uncertainty is quantified according to IEC } 61400-12-1 \text { (2005). May also be tested } \\
\text { according to the new IEC } 61400-12-1 \text { (forthcoming) to give sensitivity of the lidar to } \\
\text { external conditions. }\end{array}$ \\
\hline References & $\begin{array}{l}\text { Browning and Wexler (1968); Emeis (2010); Clifton et al. (2013); and Sathe et al. } \\
\text { (2015). }\end{array}$ \\
\hline
\end{tabular}




\subsection{Flow Modeling to Convert Wind Lidar Measurements to Point Values}

Flow modeling may be carried out in advance of a measurement campaign to confirm that the combination of flow conditions, lidar siting, and measurement methods gives sufficiently accurate data. As an alternative, the flow modeling may be carried out during or after the campaign to provide numerical factors that can be used to scale the measured data to point values (Table 2).

The flow model may be a relatively simple linear flow model, a computational fluid dynamics (CFD) model, or a more complex numerical weather prediction model. The chosen flow model should have been shown to work in the terrain and weather conditions at the site, as well as at this resolution.

Table 2. Flow Modeling to Convert Wind Lidar Measurements to Point Values

\begin{tabular}{|c|c|}
\hline Issue & Description \\
\hline Data needs & Wind speed and direction at a point or in a profile \\
\hline Situation & $\begin{array}{l}\text { Complex flow resulting from flow over or around terrain or high spatial variability because } \\
\text { of patchy land cover (especially forested land) }\end{array}$ \\
\hline Method & $\begin{array}{l}\text { A flow model is used to calculate flows around a ridge or other terrain. Results from the } \\
\text { flow model are used to show how lidar or cups would have quantified the flow. The flow } \\
\text { model and post-processing can be used to compare lidar data with data from a nearby } \\
\text { met mast or met tower (Figure 12), and also against another lidar device that uses a } \\
\text { different measurement method. }\end{array}$ \\
\hline Pros & Works with any lidar that uses a well-defined scan geometry \\
\hline \multirow[t]{4}{*}{ Cons } & $\begin{array}{l}\text { Flow modeling requires good terrain and vegetation information, is more difficult where } \\
\text { there is strong thermal forcing, and is highly sensitive to model parameterization. Results } \\
\text { will also be dependent on the accuracy of the lidar measurement model. }\end{array}$ \\
\hline & $\begin{array}{l}\text { An accurate estimate of the flow distortion in steep terrain or in areas that experience a } \\
\text { strong diurnal cycle of surface heating and cooling may be difficult, as these effects are } \\
\text { not always included in flow models. }\end{array}$ \\
\hline & $\begin{array}{l}\text { The sensitivity of the scaling process to the lidar scan design, including the probe length, } \\
\text { time resolution, and angular resolution, is not clear at this time. For example, using a lidar } \\
\text { with probe lengths less than the grid spacing may improve the correlation between the } \\
\text { lidar and the computational models, but this has not been confirmed. }\end{array}$ \\
\hline & $\begin{array}{l}\text { Consideration must be given to the uncertainties associated with the model. In particular, } \\
\text { if the measurements adjusted by the model are themselves to be used to validate a flow } \\
\text { model, care must be taken to avoid circular logic and self-fulfilling requirements. }\end{array}$ \\
\hline Validation & $\begin{array}{l}\text { Data from met towers and Doppler wind lidar devices that are collocated or separated by } \\
\text { a range of distances can be compared to results from flow models. }\end{array}$ \\
\hline References & $\begin{array}{l}\text { Bingöl et al. (2009), Boquet et al. (2009b), Harris et al. (2010), Bradley et al. (2012), Pitter } \\
\text { et al. (2012), Wagner and Bejdic (2014), and Klaas et al. (forthcoming). }\end{array}$ \\
\hline
\end{tabular}

Flow modeling is not always simple or straightforward. It must be carried out by experts and should be used with care. It requires accurate terrain models and information about surface cover and vegetation. It is more difficult to do accurately where there is strong thermal forcing. Some 
models are highly sensitive to user choices such as model parameterization. Results will also be dependent on the accuracy of the lidar measurement model. The end user should consider if the cost and potential benefits of carrying out flow modeling are warranted for their situation.

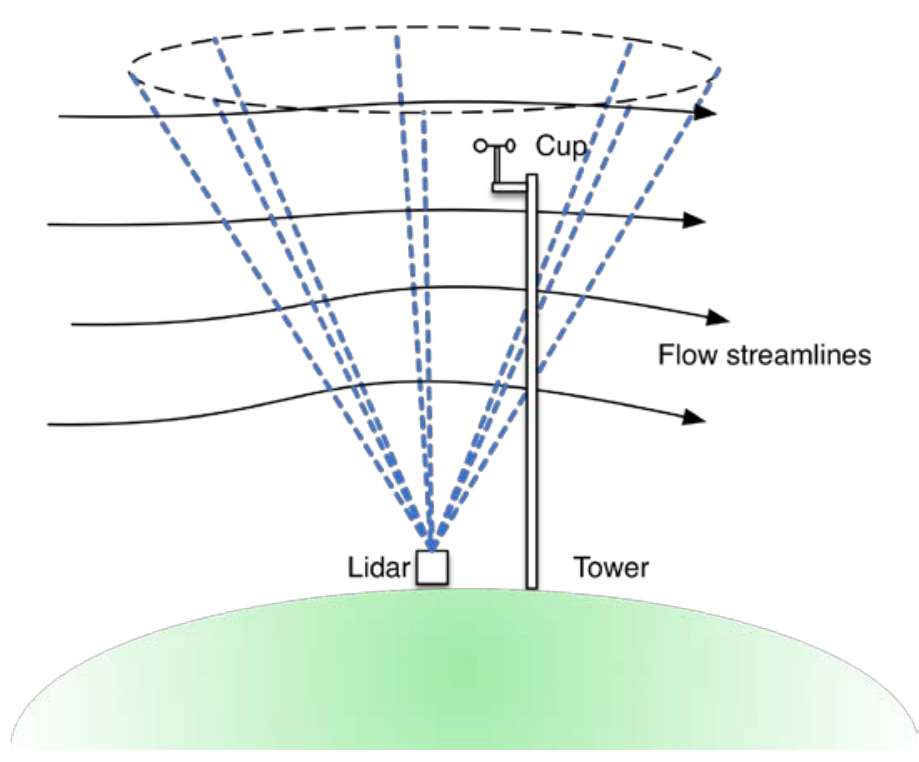

Figure 12. An illustration of the effect of terrain on the flow in the volume observed by a profiling Doppler wind lidar versus the flow observed by a point measurement on a tower

Blue lines indicate the extent of the scanning cone. 


\subsection{Flow Reconstruction from Conical Scans Without Assuming Homogeneous Flow}

The standard flow reconstruction method documented in Table 1 assumes that the flow is homogenous. This use case, presented in Table 3, applies a different flow reconstruction method to the same data to reconstruct the flow vector.

Table 3. Flow Reconstruction from Conical Scans Without Assuming Homogeneous Flow

\begin{tabular}{ll}
\hline Issue & Description \\
\hline Data needs & Wind speed and direction at a point or in a profile \\
\hline Situation & $\begin{array}{l}\text { Complex flow resulting from flow over or around terrain or high spatial variability caused } \\
\text { by patchy land cover (especially forested land) }\end{array}$ \\
\hline Method & $\begin{array}{l}\text { Radial wind speeds from different beams and at various heights are combined in some } \\
\text { form of model. For example, measurements may be combined using more physical fluid } \\
\text { dynamics assumptions and/or taking the terrain complexity into account. Other } \\
\text { approaches do not require terrain data or fluid dynamics modeling, but instead use } \\
\text { statistics to find the optimum flow field (e.g., the optimal interpolation method described } \\
\text { in Choukulkar et al. [2012]). }\end{array}$ \\
\hline Pros & $\begin{array}{l}\text { Delivers real-time wind profiles with increased accuracy compared to basic DBS lidar. } \\
\text { Also works with five-beam pulsed lidars. }\end{array}$ \\
\hline Cons & $\begin{array}{l}\text { Real-time processing requires additional time and is only applied to 10-min-average } \\
\text { data. }\end{array}$ \\
\hline $\begin{array}{l}\text { Other physical assumptions are made and may limit the application in IEC 61400-12-1 } \\
\text { (2005) Type B terrain (at the time of writing). }\end{array}$ \\
\hline $\begin{array}{l}\text { As with standard conical scan-based techniques } \\
\text { Krishnamurthy and Boquet (2014) propose a methodology to estimate uncertainty based } \\
\text { on terrain complexity and roughness. }\end{array}$ \\
\hline $\begin{array}{l}\text { References } \\
\text { Choukulkar et al. (2012), Boquet et al. (2012), Schlipf et al. (2012), Wagner and Schmitt } \\
\text { (2012), Krishnamurthy and Boquet (2014), and Wagner and Bejdic (2014). }\end{array}$ \\
\hline
\end{tabular}




\subsection{Vertical Beam to Reduce Uncertainty in the Vertical Component}

Most flow reconstruction methods require all three of the wind components to be estimated from a set of measurements. In the use case presented in Table 4, the vertical component is measured directly by the lidar (Figure 13), reducing the complexity of the flow reconstruction.

Table 4. Vertical Beam Use to Reduce Uncertainty in the Vertical Component

\begin{tabular}{|c|c|}
\hline Issue & Description \\
\hline Data needs & Vertical wind speed at a single height or in a profile \\
\hline Situation & $\begin{array}{l}\text { Complex flow resulting from flow over or around terrain or high spatial variability caused } \\
\text { by patchy land cover (especially forested land) }\end{array}$ \\
\hline Method & $\begin{array}{l}\text { A vertical beam is emitted by the lidar. Because the vertical beam measures only the } \\
\text { vertical component of the wind, this allows the vertical component to be measured more } \\
\text { accurately than the method of fitting a number of off-vertical line-of-sight velocity } \\
\text { measurements. A known vertical velocity means that line-of-sight velocity data can be } \\
\text { better reduced to a horizontal wind vector. }\end{array}$ \\
\hline Pros & Reduces uncertainty in measurements of the vertical component \\
\hline \multirow[t]{2}{*}{ Cons } & $\begin{array}{l}\text { The vertical component is small and therefore has a small Doppler signal that may be } \\
\text { difficult to measure accurately. In addition, the vertical component of the wind varies } \\
\text { depending on location and flow type. }\end{array}$ \\
\hline & $\begin{array}{l}\text { Depending on the measurement method, a vertical beam at a single location may not } \\
\text { provide a unique solution to the wind vector. }\end{array}$ \\
\hline Validation & $\begin{array}{l}\text { Vertical component measurements can be compared to three-dimensional sonic } \\
\text { anemometers. Horizontal wind speeds can be compared to met towers. }\end{array}$ \\
\hline
\end{tabular}

Figure 13. Use of a vertical beam to constrain the results of flow reconstruction from a conical scan 


\subsection{Use of a Smaller Lidar Measurement Volume to Reduce Differences Compared to Cups}

A lidar using a conical scan measures the line-of-sight velocity along many azimuth angles from a central point. As a result, it measures a larger volume than a cup or sonic anemometer. The use case presented in Table 5 modifies the scanning geometry to reduce the measurement volume.

Table 5. Use of a Smaller Lidar Sampling Volume to Reduce Differences Compared to Cups

\begin{tabular}{ll}
\hline Issue & Description \\
\hline Data needs & Wind speed and direction at a point or in a profile \\
Situation & Any inhomogeneous flows \\
Method & The measurement volume is reduced to make the total volume of air sampled by the \\
Doppler wind lidar measurement closer to that of a cup anemometer (Figure 14). \\
A smaller measurement volume can be implemented by: \\
- Using a smaller cone angle to reduce the cone width \\
- $\begin{array}{l}\text { Reducing the probe length by using shorter-duration pulses, optical focusing, or } \\
\text { improved signal processing }\end{array}$ \\
Pros \\
Cons \\
lidars reduces cone width (see the multi-lidar methods in Table 10).
\end{tabular}




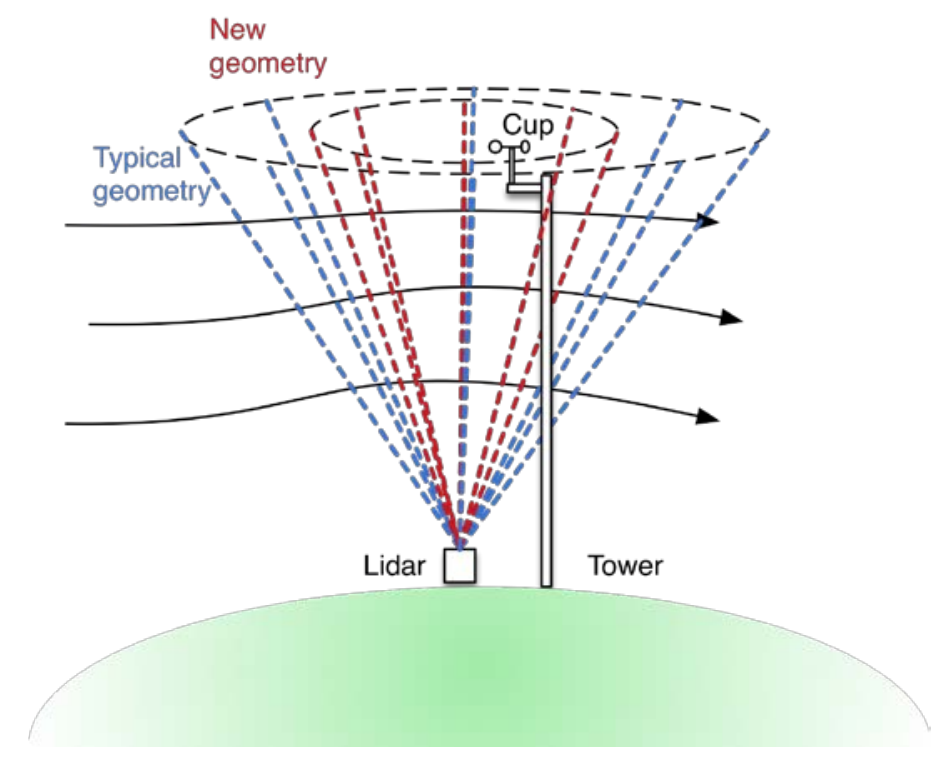

Figure 14. Reducing the cone angle to reduce the volume of a conical scan 


\subsection{Use of a Short Met Mast to Scale Measurements}

An on-site met mast can be used as a reference measurement to scale lidar measurements (Table 6).

Table 6. Use of a Met Tower to Scale Lidar Measurements

\begin{tabular}{ll}
\hline Issue & Description \\
\hline Data needs & Wind speed and direction at a point or in a profile \\
Situation & $\begin{array}{l}\text { Complex flow resulting from flow over or around terrain or high spatial variability } \\
\text { because of patchy land cover (especially forested land) }\end{array}$ \\
\hline Method & $\begin{array}{l}\text { A met mast on site is used to correct the lidar measurements. The correction factors } \\
\text { can be found directly at the common measurement heights if the two instruments are } \\
\text { collocated. The correction factors at higher heights can be derived from those } \\
\text { measured at lower heights. If the lidar and met mast are not collocated, the correction } \\
\text { factors may be found through the use of flow modeling. }\end{array}$ \\
\hline Pros & $\begin{array}{l}\text { Works with any measurement device and can be applied after postprocessing } \\
\text { Cons }\end{array}$ \\
$\begin{array}{l}\text { The correction factors at higher heights above the met mast will have to be derived } \\
\text { from lower common heights and may therefore contain some uncertainty. There will } \\
\text { also be uncertainty if the lidar is not collocated with the met mast. }\end{array}$ \\
Validation & $\begin{array}{l}\text { Correction factors from collocated tall met towers and lidars or separated from a } \\
\text { distance can be measured and estimated. The estimated and measured correction } \\
\text { factors will be compared. }\end{array}$ \\
\hline
\end{tabular}




\subsection{Use of Conical Sector or Vertical Slice Scans to Qualitatively Identify Flow Features}

Lidar devices can be used to qualitatively identify flows such as wakes or recirculation, as described in Table 7.

Table 7. Using Conical Sectors or Vertical Slices to Qualitatively Identify Flows

\begin{tabular}{|c|c|}
\hline Issue & Description \\
\hline Data needs & Qualitative indication of unusual flow features \\
\hline Situation & Any complex flow condition \\
\hline Method & $\begin{array}{l}\text { Use vertical slice scans (constant azimuth, varying elevation) or conical sector scans } \\
\text { (constant elevation, varying azimuth) scans to measure radial velocity over planes. The } \\
\text { lidar can be on the ground or on a turbine nacelle. Flow heterogeneity can be seen clearly } \\
\text { (Figure 15). }\end{array}$ \\
\hline Pros & $\begin{array}{l}\text { Works with any lidar device capable of arbitrary scan geometries. Vertical slices may be } \\
\text { used to show regions of flow recirculation. }\end{array}$ \\
\hline \multirow[t]{2}{*}{ Cons } & $\begin{array}{l}\text { Interpreting data may require some conceptual model. Flow reconstruction requires careful } \\
\text { selection of homogenous flow regions. }\end{array}$ \\
\hline & $\begin{array}{l}\text { Slice scans performed along the mean wind direction have limited applicability for wind } \\
\text { field reconstruction (Pichugina et al. 2008). }\end{array}$ \\
\hline Validation & Radial velocity data can be compared to sonic anemometer measurements on towers. \\
\hline References & Barkwith and Collier (2011), and Banta et al. (2015) \\
\hline
\end{tabular}



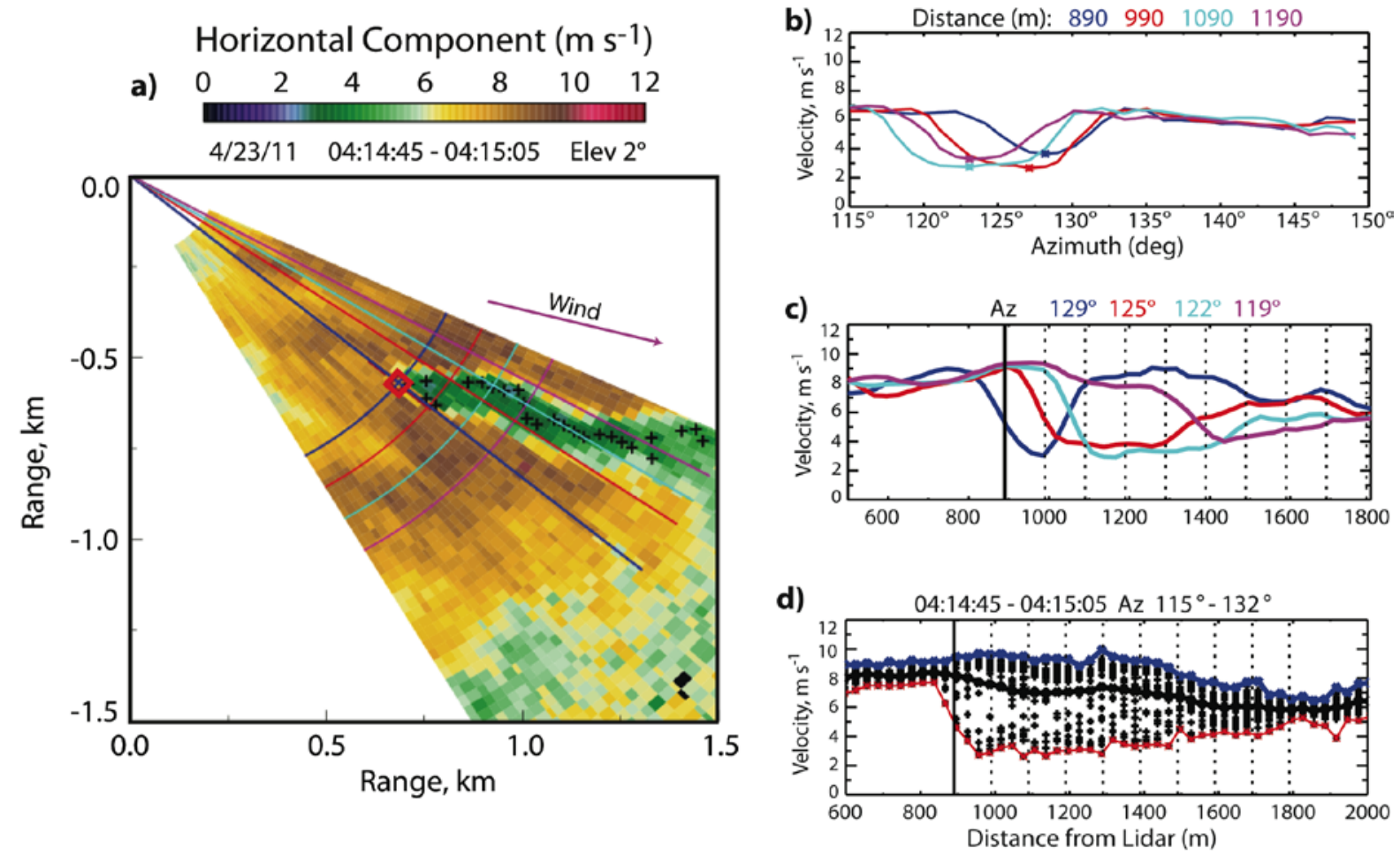

Figure 15. Using a low-elevation conical sector scan to detect and quantify a wind turbine wake

Panels include a) the raw scan data; b) the wind speed profile at selected ranges from the lidar; c) the horizontal velocity at selected azimuth angles as a function of distance; d) horizontal velocity range as a function of range as in (c) for all rays of data in the scan depicted in (a). Source: Banta et al. (2015) 


\subsection{Flow Reconstruction from Conical Sector and Vertical Slice Scans in Complex Flows}

As shown in Table 8, measurements made using conical sector scans or vertical slices can also be used to estimate the wind vector within the measurement domain. The wind vector may be estimated at multiple points in the domain, or it might be a bulk value for the entire domain.

Table 8. Flow Reconstruction from Conical Sector Scans and Vertical Slices in Complex Flows

\begin{tabular}{ll}
\hline Issue & Description \\
\hline Data needs & Wind speed and direction across a wide area or from a distance \\
Situation & All flows \\
Method & $\begin{array}{l}\text { A single scanning lidar is used to measure line-of-sight wind speed at one or more } \\
\text { azimuth and elevation angles. Scans are made by a single scanning lidar so that the line- } \\
\text { of-sight wind speed is measured at several locations in a short period of time. } \\
\text { The wind vector can be calculated from the scan data using the standard assumption of } \\
\text { flow homogeneity (see Section 6.1), or without assuming homogeneity (see Section 6.3). }\end{array}$ \\
\hline Pros & $\begin{array}{l}\text { Measurements at a distance from the Doppler wind lidar can be converted into a wind } \\
\text { vector if assumptions are made about the flow field. For example, it may be assumed that } \\
\text { the wind speed changes only with height and not horizontally. }\end{array}$ \\
\hline Cons & $\begin{array}{l}\text { Conversion to a flow vector requires some assumption about the homogeneity of the flow } \\
\text { field. Trade-offs must be made among range, pulse length, and integration time. }\end{array}$ \\
Validation & $\begin{array}{l}\text { The measurement domain can be defined to include one or more towers or other remote } \\
\text { sensing devices that can be used to check the wind field reconstruction. }\end{array}$ \\
\hline References & $\begin{array}{l}\text { Banta et al. (2002); Choukulkar (2012); Pichugina et al. (2012), and Krishnamurthy et al. } \\
\text { (2013) }\end{array}$ \\
\hline
\end{tabular}




\subsection{Scanning Lidar Use for Quantitative Analysis of Wakes}

The methods used for flow reconstruction from conical sector or slice scan data can be modified so that they include ways to quantify the spatial extent and magnitude of wakes within the measurements, as described in Table 9. This approach allows more information to be extracted from the lidar data than would otherwise be possible.

Table 9. Scanning Lidar Use for Quantitative Analysis of Wakes

\begin{tabular}{|c|c|}
\hline Issue & Description \\
\hline Data needs & Wind speed and direction around a turbine and in the wake, measured from a distance \\
\hline Situation & $\begin{array}{l}\text { Flows that include turbine wakes. High spatial inhomogeneity in a turbine wake, as well as } \\
\text { between the wake and ambient flow, invalidates the assumption of homogenous flow. }\end{array}$ \\
\hline Concept & $\begin{array}{l}\text { Arc scans by lidar are analyzed assuming that the ambient flow is homogenous but that a } \\
\text { wake is also present. The wake takes the form of a superimposed Gaussian velocity } \\
\text { deficit that is characterized by the height, width, and magnitude of the deficit. }\end{array}$ \\
\hline Pros & Allows the detection and characterization of wakes \\
\hline \multirow[t]{2}{*}{ Cons } & $\begin{array}{l}\text { Interpreting the data from the lidar requires a conceptual model of the flow in the wake, } \\
\text { which might change depending on atmospheric stability. Extending the model to multiple } \\
\text { or superimposed wakes is nontrivial. }\end{array}$ \\
\hline & $\begin{array}{l}\text { Lidar requires a finite amount of time to sample the winds at each range gate, azimuth } \\
\text { angle, and elevation angle, and to change these parameters to sample different locations } \\
\text { in the flow. Current lidar designs are not always able to measure or change sampling } \\
\text { locations fast enough to achieve the spatial and temporal resolution that is required for } \\
\text { this use case. }\end{array}$ \\
\hline Validation & $\begin{array}{l}\text { Can be tested using data from met towers or several intersecting lidars. Vertical profilers } \\
\text { using conical scans and assuming flow homogeneity should not be used to validate the } \\
\text { wake effect because of the effect of flow inhomogeneity in the wake on the recovered } \\
\text { data. }\end{array}$ \\
\hline References & $\begin{array}{l}\text { Bingöl et al. (2010), Käsler et al. (2010), Trujillo et al. (2011), Butler and Quail (2012), } \\
\text { Butler (2013), lungo, Wu, and Porté-Agel (2013), Smalikho et al. (2013), Aitken and } \\
\text { Lundquist (2014), Aitken et al. (2014), Butler (2014); Gallacher and More (2014), and } \\
\text { Banta et al. (2015). }\end{array}$ \\
\hline
\end{tabular}




\subsection{Multiple Lidar Use to Measure Wind Vectors}

Measurements using two or more lidar systems allow the same volume to be probed from different directions, reducing the need for extensive assumptions about the flow, as described in Table 10.

Table 10. Multiple Lidar Use to Measure Wind Vectors

\begin{tabular}{|c|c|}
\hline Issue & Description \\
\hline Data needs & Three-dimensional wind fields in complex flows \\
\hline Situation & Any location or flow conditions, particularly known complex flow \\
\hline \multirow[t]{2}{*}{ Method } & $\begin{array}{l}\text { Multiple lidar measurements, also known as dual-Doppler, triple Doppler, or "musketeer" } \\
\text { methods. Coordinated scans are made by multiple scanning lidars, so that the line-of- } \\
\text { sight wind speed is measured at the same point in space from two or more directions. } \\
\text { The coincident measurements are used to derive a wind speed at a "virtual anemometer" } \\
\text { location. Wind speeds can also be measured at many different heights, creating a "virtual } \\
\text { tower." }\end{array}$ \\
\hline & $\begin{array}{l}\text { No assumption need be made about local flow homogeneity. If two lidars are used, } \\
\text { however, the vertical velocity must be assumed to be zero. If three lidars are used, the } \\
\text { line-of-sight wind speed can be measured at the same point in space from three } \\
\text { directions. }\end{array}$ \\
\hline \multirow[t]{4}{*}{ Pros } & Measurements can be taken at some distance from the lidar. \\
\hline & $\begin{array}{l}\text { The horizontal and vertical extent of the averaging volume can be reduced compared to a } \\
\text { conical scan, depending on the scan geometry, pointing precision, and distance from the } \\
\text { lidar to the virtual tower. }\end{array}$ \\
\hline & $\begin{array}{l}\text { This method does not require an assumption of flow homogeneity. If three lidars are } \\
\text { used, there is no need to assume zero net vertical velocity. }\end{array}$ \\
\hline & $\begin{array}{l}\text { High time resolution can be achieved as the different beam orientations required for wind } \\
\text { vector characterization are obtained from multiple beams, and so the time overhead that } \\
\text { scanning between beam orientations entails is reduced. This may allow better agreement } \\
\text { between lidar and met mast turbulence intensity measurements. }\end{array}$ \\
\hline \multirow[t]{5}{*}{ Cons } & Two or more scanning Doppler wind lidars are required. \\
\hline & $\begin{array}{l}\text { Devices must be carefully aligned, and the alignment must be checked regularly to } \\
\text { maintain a small measurement volume at long distances. }\end{array}$ \\
\hline & $\begin{array}{l}\text { If data are required at a high frequency (e.g., } 1 \mathrm{~Hz} \text { ) rather than averaged over } 10 \mathrm{~min} \text {, the } \\
\text { devices must be time synchronized. }\end{array}$ \\
\hline & $\begin{array}{l}\text { It is unclear how scans should be set up to obtain representative average and standard } \\
\text { deviations of wind speed at multiple virtual anemometer locations. }\end{array}$ \\
\hline & $\begin{array}{l}\text { The number of locations that can be accurately probed is limited by the slew rate of the } \\
\text { lidar and the sensitivity of the detector (i.e., the speed with which line-of-sight wind speed } \\
\text { can be estimated). }\end{array}$ \\
\hline Validation & $\begin{array}{l}\text { Can be tested against a met tower or by positioning lidar, sodar, or radar profiling devices } \\
\text { to sample at the location of the intersecting beams. }\end{array}$ \\
\hline References & $\begin{array}{l}\text { Calhoun et al. (2006); Mikkelsen et al. (2008); Newsom et al. (2008); Dreschel et al. } \\
\text { (2010); Clive (2014), and Newsom et al. (2015), }\end{array}$ \\
\hline
\end{tabular}




\section{Conclusions}

It is important to recognize that complex flows cause problems for all methods of measuring winds. For anemometers on towers, the issue is how representative the measurement is. For example, does the measurement represent some area around the measurement site, or is it only applicable to the site itself? This is a complicated issue that varies diurnally and seasonally, and depends on changing meteorological conditions. The problem for tower measurements is compounded when winds aloft are calculated by vertical extrapolation from measurements at lower heights using a standardized wind profile, such as the power law profile. This extrapolation approach cannot be applied with confidence in complex flows. For remote sensors - including Doppler lidar - that measure a radial or line-of-sight component of the wind at multiple azimuth angles, the algorithms that calculate the mean wind from these measurements usually assume horizontal uniformity (horizontal homogeneity) of the winds at each vertical level. In complex terrain, however, the flows are not, in general, horizontally homogeneous.

The critical questions for users of lidar data in complex flow, then, are:

- How big is the difference compared to a point measurement for a given use case?

- How do results compare with other methods of determining the wind vector aloft?

This report gives background on the reasons why Doppler wind lidar and traditional methods of measuring wind data in complex flow situations can give different results and suggests some ways to mitigate the related effects.

Several different use cases for Doppler wind lidar in complex flow are introduced, including:

- Use cases based on conical scanning lidar

- Flow reconstruction from conical scans in homogenous flows

- Flow modeling to convert wind lidar measurements to point values

- Flow reconstruction from conical scans without assuming homogeneous flow

- Vertical beam use to reduce uncertainty in the vertical component

- Use of a smaller lidar sampling volume to reduce differences compared to cups

○ Use of a short met mast to scale lidar measurements.

- Use cases based on scanning lidar

- Use of conical sector or slice scans to qualitatively identify flow features

- Flow reconstruction from conical sector or slice scans in complex flows

- Scanning lidar use for quantitative analysis of wakes

○ Multiple lidar use to measure wind vectors.

Most of these use cases can be validated using met towers or other in-situ measurements. Applying this in-situ validation approach to every lidar measurement will be expensive, though, so it may instead be advisable to develop physics-based models for the bias and uncertainty of the different use cases. These models should take the flow types and the measurement setup into 
account. If these bias and uncertainty models are validated using available data, this approach would allow validated estimates of the bias uncertainty to be generated in new conditions and sites without the need for new in situ validation.

Flow modeling has been shown to have a useful role to play in postprocessing lidar data. It may also be useful for testing use cases before a lidar is deployed. In this application, a high-fidelity flow model could be used to simulate flows at a site under a range of wind speeds and directions, as well as at different times of day. The data from the flow model could be used to simulate results from lidar measurements (including postprocessing) and results from cup anemometers. If the difference between the cup and the lidar is greater than acceptable for this application, a different combination of lidar measurement and analysis methods should be used.

This effort has identified several technical challenges regarding measuring wind fields in complex flow, mostly related to the heterogeneity of complex flow and the difficulty of relating line-of-sight data back to a wind vector. A key observation is that data from volumetric measurement methods and point measurements are inherently different. Several use cases have demonstrated positive results in addressing this problem, including:

- Flow modeling to convert wind lidar measurements to point values (Section 6.2)

- Flow reconstruction from conical scans without assuming homogenous flow (Section 6.3)

- Multi-lidar (Section 6.10).

These use cases may potentially be considered valid use cases for lidar in complex flow.

Several preliminary recommendations are identified for the use of lidar in complex flow:

- Define complex flow based on terrain or meteorological conditions.

- Select an appropriate measurement method for the use case.

- Validate each individual use case.

- Follow the RP15 validation methods for simple flow conditions (Clifton et al. 2013).

These recommendations, along with other sources, are intended for future use in creating a recommended practice for using lidar in complex flow situations. A recommended practice will lead to increased confidence in the use of lidar for wind energy applications.

The need for point measurements for wind energy applications is partly historic because of the familiarity of the wind energy industry with cup anemometers. Acceptance of lidar data is thus reliant on being able to show how lidar and cup anemometer measurements compare; however, a wind turbine's power is better described by the total flow through the rotor (see Wagner et al. [2009]), and so there may potentially be some benefit to the use of a volumetric measurement to measure wind resources. Systematic quantitative studies are needed to understand these issues and determine how best to address them. 


\section{References}

Abiven, C., Palma, J., Brady, O. (2011). "High-Frequency Field Measurements and TimeDependent Computational Modelling for Wind Turbine Siting." Journal of Wind Engineering and Industrial Aerodynamics (99: 2-3); pp. 123-129. Accessed July 30, 2015. http://dx.doi.org/10.1016/j.jweia.2010.12.006.

Aitken, M.L., Banta, R.M., Pichugina, Y.L., Lundquist, J.K. (2014). "Quantifying Wind Turbine Wake Characteristics from Scanning Remote Sensor Data." Journal of Atmospheric and Oceanic Technology (31:4); pp. 765-787. Accessed July 30, 2015. http://dx.doi.org/10.1175/JTECH-D13-00104.1.

Aitken, M.L., Lundquist, J.K. (2014). "Utility-Scale Wind Turbine Wake Characterization Using Nacelle-Based Long-Range Scanning Lidar." Journal of Atmospheric and Oceanic Technology, (31:7); pp. 1529-1539. Accessed July 30, 2015. http://dx.doi.org/10.1175/JTECH-D-13-00218.1.

Banta, R.M., Newsom, R.K., Lundquist, J.K., Pichugina, Y.L., Coulter, R.L., Mahrt, L. (2002). "Nocturnal Low-Level Jet Characteristics over Kansas during CASES-99." Boundary-Layer Meteorology (105:2); pp. 221-252.

Banta, R.M., Pichugina, Y.L., Brewer, W.A., Lundquist, J.K., Kelley, N.D., Sandberg, S.P., Alvarez, R.J. II; Hardesty, R.M., Weickmann, A.M. (2015). "3D Volumetric Analysis of Wind Turbine Wake Properties in the Atmosphere Using High-Resolution Doppler Lidar." Journal of Atmospheric and Oceanic Technology (32:5); pp. 904-914. Accessed July 30, 2015. http://dx.doi.org/10.1175/JTECH-D-14-00078.1.

Barkwith, A., Collier, C.G. (2011). "Lidar Observations of Flow Variability over Complex Terrain.” Meteorological Applications (18:3); pp. 372-382.

Bingöl, F., Mann, J., Foussekis, D. (2009). "Conically Scanning Lidar Error in Complex Terrain.” Meteorologische Zeitschrift (18:2); pp. 189-195. Accessed July 30, 2015. http://dx.doi.org/10.1127/0941-2948/2009/0368.

Bingöl, F., Mann, J., Larsen, G.C. (2010). "Light Detection and Ranging Measurements of Wake Dynamics Part I: One-Dimensional Scanning.” Wind Energy (13:1); pp. 51-61. Accessed July 30, 2015. http://dx.doi.org/10.1002/we.352.

Boquet, M., Parmentier, R., Sauvage, L., Cariou, J.P. (2009a). "Theoretical and CFD Analysis of Pulsed Doppler Lidar Wind Profile Measurement Process in Complex Terrain." Presented at the Eighth International Symposium on Tropospheric Profiling, Delft, Holland.

Boquet, M., Ribstein, B., Parmentier, R., Cariou, J.P., Sauvage, L., Albergel, A. (2009b). "Analysis and Optimization of the WINDCUBE Lidar Measurement Process in Complex Terrain." Poster 584, presented at the European Wind Energy Conference and Exhibition, Marseilles, France. 
Boquet, M., Comas, X., Martinez, E. (2012). "Application of Lidar for Assessment of the Wind Resource in Complex Terrain." Presented at German Wind Energy Conference DEWEK, Bremen, Germany.

Bradley, S., Perrott, Y., Behrens, P., Oldroyd, A. (2012). "Corrections for Wind-Speed Errors from Sodar and Lidar in Complex Terrain.” Boundary-Layer Meteorology (143:1); pp. 37-48. Accessed July 30, 2015. http://dx.doi.org/10.1007/s10546-012-9702-0.

Browning, K.A., Wexler, R. (1968). “The Determination of Kinematic Properties of a Wind Field Using Doppler Radar." Journal of Applied Meteorology (7:1); pp. 105-113. Accessed July 30, 2015. http://dx.doi.org/10.1175/1520-0450(1968)007<0105:TDOKPO>2.0.CO;2.

Butler, J. N., (2013). “Comparison of Offshore Scanning Wind Lidar Wake Measurements with Industry Standard Wake Models,” Presented at EWEA Offshore, Frankfurt, Germany.

Butler, J. N., (2014). “Assessment of Complex Wind Turbine Wake Flow Using Scanning Wind Lidar Measurements and Numerical Analysis Techniques," Ph.D. Thesis, University of Strathclyde

Butler, J., and F. Quail. (2012). "Comparison of a 2nd Generation LiDAR Wind Measurement Technique with CFD Numerical Modelling in Complex Terrain.” International Conference on Sustainable Power Generation and Supply (SUPERGEN 2012). http://dx.doi.org/10.1049/cp.2012.1769

Calhoun, R., Heap, R., Princevac, M., Newsom, R., Fernando, H., Ligon, D. (2006). "Virtual Towers Using Coherent Doppler Lidar during the Joint Urban 2003 Dispersion Experiment." Journal of Applied Meteorology and Climatology (45:8); pp. 1116-1126. Accessed July 30, 2015. http://dx.doi.org/10.1175/JAM2391.1.

Choukulkar, A., Calhoun, R., Billings, B., Doyle, J.D. (2012). “A Modified Optimal Interpolation Technique for Vector Retrieval for Coherent Doppler Lidar." Geoscience and Remote Sensing Letters IEEE (9:6); pp. 1132-1136.

Clifton, A., Elliott, D., Courtney, M., eds. (2013). "Ground-Based Vertically-Profiling Remote Sensing for Wind Resource Assessment." Number 15 in Expert Group Study on Recommended Practices. 1st ed. IEA. Accessed July 30, 2015. http://goo.gl/NPzjH.

Clive, P. J. M. (2008). "Compensation of Bias in Lidar Wind Resource Assessment," Wind Engineering Vol. 32 No. 5. http://dx.doi.org/10.1260/030952408786411949.

Clive, P. J. M. (2009). "How to Make Remote Wind Sensing Bankable," Presented to IEA Wind Energy Task 19: Wind Energy in Cold Climates, Vienna, Austria.

Clive, P. J. M. (2011). “In situ Site Specific Calibration of SODARs for Operation in Complex Terrain," Poster presented at the CanWEA Annual Conference, Vancouver, British Columbia.

Clive, P. J. M. (2013). “Quantifying Terrain Complexity.” Presented at IEA R\&D Wind Task 11 Topical Expert Meeting 75. 
Clive, P. J. M. (2014). "Lidar Observations of the Compression Zone and Capabilities as a Turbulence Instrument." Presented to the Power Curve Working Group, Glasgow, Scotland. Accessed November 25, 2015. http://goo.gl/MzcNiI

Clive, P. J. M. (2015). "Lidar Use Cases for the Acquisition of High Value Datasets." Poster presented at the EWEA Offshore Wind Conference, Copenhagen, Denmark. Accessed July 30, 2015. http://www.ewea.org/offshore2015/conference/allposters/PO179.pdf.

Drechsel, S., Mayr, G.J., Chong, M., Chow, F.K. (2010). "Volume Scanning Strategies for 3D Wind Retrieval from Dual-Doppler Lidar Measurements." Journal of Atmospheric and Oceanic Technology (27:11); pp. 1881-1892.

Emeis, S. (2010). Surface-Based Remote Sensing of the Atmospheric Boundary Layer. Volume 40 of Atmospheric and Oceanographic Sciences Library. Springer Netherlands. Accessed July 30, 2015. http://www.springer.com/us/book/9789048193394.

Gallacher, D., and More, G. (2014). "Lidar Measurements and Visualisation of Turbulence and Wake Decay Length," Poster presented at EWEA Annual Conference, Barcelona, Spain

Harris, M., Locker, I., Douglas, N., Girault, R., Abiven, C., Brady, O. (2010). "Validated Adjustment of Remote Sensing Bias in Complex Terrain using CFD." Presented at EWEC 2010, Warsaw, Poland.

IEC 61400-1 (2010). International Electrotechnical Commission (IEC): IEC 61400-1: Wind Turbines-Part 1: Design Requirements. International Standard 61400-01, 3rd ed., Amendment 1. Geneva: IEC.

IEC 61400-12-1 (2005). International Electrotechnical Commission (IEC): IEC 61400-12-1: Wind turbines - Part 12-1: Power performance measurements of electricity producing wind turbines International Standard 61400-12-1. 1st ed. Geneva: IEC.

IEC 61400-12-1 Ed. 2 CD (2015). International Electrotechnical Commission (IEC): IEC 6140012-1 Ed. 2: Wind turbines - Part 12-1: Power performance measurements of electricity producing wind turbines, Committee Draft (CD), 2015-07-22.

Iungo, G.V., Wu, Y.-T., Porté-Agel, F. (2012). "Field Measurements of Wind Turbine Wakes with Lidars." Journal of Atmospheric and Oceanic Technology (30:2); pp. 274-287. Accessed July 30, 2015. http://dx.doi.org/10.1175/JTECH-D-12-00051.1.

Jaynes, D., Courtney, M. (2011). "Best Practice Recommendations for Lidar Wind Resource Assessment." 59th IEA Wind Topical Experts Meeting, Ad-Hoc Lidar Group.

Klaas, T., Pauscher, L., Callies, D. (forthcoming). “A Comparison of LiDAR and Mast Measurements in Complex Terrain and Its Simulation Using CFD." Accepted for publication in Meteorologische Zeitschrift. 
Käsler, Y., Rahm, S., Simmet, R., Kühn, M. (2010). "Wake Measurements of a Multi-MW Wind Turbine with Coherent Long-Range Pulsed Doppler Wind Lidar." Journal of Atmospheric and Oceanic Technology (27:9); pp. 1529-1532. Accessed July 30, 2015. http://dx.doi.org/10.1175/2010JTECHA1483.1.

Krishnamurthy, R., Choukulkar, A., Calhoun, R., Fine, J., Oliver, A., Barr, K.S. (2013). "Coherent Doppler Lidar for Wind Farm Characterization." Wind Energy (16:2); pp. 189-206. Accessed July 30, 2015.http://dx.doi.org/10.1002/we.539.

Krishnamurthy, R., Boquet, M. (2014). "Case Studies of WINDCUBE Measurement Uncertainty for Complex Terrain Using Flow Complexity Recognition.” Presented at EWEA 2014, Barcelona, Spain.

Lhermitte, Roger M. 1966. "Application of Pulse Doppler Radar Technique to Meteorology." Bulletin of the American Meteorological Society (47:9), pp. 703-710.

Lundquist, J.K., Churchfield, M.J., Lee, S., Clifton, A. (2015). "Quantifying Error of Lidar and Sodar Doppler Beam Swinging Measurements of Wind Turbine Wakes Using Computational Fluid Dynamics." Atmospheric Measurement Techniques (8:2); pp. 907-920.

Mikkelsen, T., Mann, J., Courtney, M., Sjöholm, M. (2008). "Windscanner: 3-D Wind and Turbulence Measurements from Three Steerable Doppler Lidars." IOP Conference Series: Earth and Environmental Science (1:1). Accessed July 30, 2015. http://dx.doi.org/10.1088/1755$\underline{1315 / 1 / 1 / 012018 .}$

Moore, K. (2011). "Recommended Practices for the Use of Sodar in Wind Energy Resource Assessment." 59th IEA Wind Topical Experts Meeting Ad-Hoc Sodar Group.

Newsom, R.K., Berg, L.K., Shaw, W. J., Fischer, M.L. (2015). “Turbine-Scale Wind Field Measurements Using Dual-Doppler Lidar.” Wind Energy (18:2); pp. 219-235. Accessed July 30, 2015. http://dx.doi.org/10.1002/we.1691.

Newsom, R.K., Calhoun, R., Ligon, D., Allwine, J. (2008). "Linearly Organized Turbulence Structures Observed Over a Suburban Area by Dual-Doppler Lidar.” Boundary-Layer Meteorology (127:1); pp. 111-130.

Papadopoulos, K., Stefantos, N., Paulsen, U., Morfiadakis, E. (2001). "Effects of Turbulence and Flow Inclination on the Performance of Cup Anemometers in the Field." Boundary-Layer Meteorology (101:1); pp. 77-107.

Pichugina, Y.L., Banta, R.M., Brewer, W.A., Sandberg, S.P., Hardesty, R.M. (2012). “Doppler Lidar-Based Wind-Profile Measurement System for Offshore Wind-Energy and Other Marine Boundary Layer Applications." Journal of Applied Meteorology and Climatology (51); pp. 327349. 
Pichugina, Y.L., Banta, R.M., Kelley, N.D., Jonkman, B.J., Tucker, S.C., Newsom, R.K., Brewer, W.A. (2008). "Horizontal-Velocity and Variance Measurements in the Stable Boundary Layer Using Doppler Lidar: Sensitivity to Averaging Procedures." Journal of Atmospheric and Oceanic Technology (25); pp. 1307-1327.

Pitter, M., Abiven, C., Vogstad, K., Harris, M., Barker, W., Brady, O. (2012). "Lidar and computational fluid dynamics for resource assessment in complex terrain." Presented at EWEA 2012, Copenhagen, Denmark.

Sathe, A., Mann, J., Vasiljevic, N., Lea, G. (2015). "A Six-Beam Method to Measure Turbulence Statistics Using Ground-Based Wind Lidars.” Atmospheric Measurement Techniques (8:2); pp. 729-740.

Schlipf, D.: Rettenmeier, A., Haizmann, F., Hofsäß, M., Courtney, M., Cheng, P. W. (2012) "Model Based Wind Vector Field Reconstruction from Lidar Data," Presented at the German Wind Energy Conference DEWEK, Bremen, Germany.

Smalikho, I.N., Banakh, V.A., Pichugina, Y.L., Brewer, W.A., Banta, R.M., Lundquist, J.K., Kelley, N.D. (2013). "Lidar Investigation of Atmosphere Effect on a Wind Turbine Wake." Journal of Atmospheric and Oceanic Technology (30:11); pp. 2554-2570. Accessed July 30, 2015. http://dx.doi.org/10.1175/JTECH-D-12-00108.1.

Troen, I., Petersen, E.L. (1989). European Wind Atlas. ISBN 87-550-1482-8. Roskilde, Denmark: Risø National Laboratory. 656 pp.

Trujillo, J.-J., Bingöl, F., Larsen, G.C., Mann, J., Kühn, M. (2011). "Light Detection and Ranging Measurements of Wake Dynamics. Part II: Two-Dimensional Scanning." Wind Energy (14:1); pp. 61-75. Accessed July 30, 2015. http://dx.doi.org/10.1002/we.402.

Wagner, L., Schmitt, C. (2012). "Measuring Wind Profiles in Complex Terrain Using Doppler Wind Lidar Systems with FCR and CFD Implementations." Presented at the German Wind Energy Conference DEWEK, Bremen, Germany.

Wagner, R., Antoniou, I., Pedersen, S. M., Courtney, M. S., Jørgensen, H. E. (2009), “The Influence of the Wind Speed Profile on Wind Turbine Performance Measurements." Wind Energy (12:4) 348-362. Accessed July 30, 2015. http://dx.doi.otg/10.1002/we.297

Wagner, R., Bejdic, J. 2014. WINDCUBE + FCR Test at Hrgud, Bosnia and Herzegovina. Volume E-0039. DTU Wind Energy, Risø, Denmark.

Wang, H., R. J. Barthelmie, A. Clifton, and S. C. Pryor. 2015. "Wind Measurements from Arc Scans with Doppler Wind Lidar." Journal of Atmospheric and Oceanic Technology, 2015/09/21.

Wylie, S. 2015. Personal Communication, "Experiments Performed with ZephIR300 Lidars against a 91m Tall Mast at the UK Remote Sensing Test Site, Pershore, UK." 